\title{
Uncertainty associated with convective wet removal of entrained aerosols in a global climate model
}

\author{
B. Croft ${ }^{1}$, J. R. Pierce ${ }^{1}$, R. V. Martin ${ }^{1,2}$, C. Hoose ${ }^{3}$, and U. Lohmann ${ }^{4}$ \\ ${ }^{1}$ Department of Physics and Atmospheric Science, Dalhousie University, Halifax, Canada \\ ${ }^{2}$ Harvard-Smithsonian Center for Astrophysics, Cambridge, MA, USA \\ ${ }^{3}$ Karlsruhe Institute of Technology, Karlsruhe, Germany \\ ${ }^{4}$ Institute of Atmospheric and Climate Science, ETH Zurich, Zurich, Switzerland
}

Correspondence to: B. Croft (croft@ mathstat.dal.ca)

Received: 3 January 2012 - Published in Atmos. Chem. Phys. Discuss.: 19 January 2012

Revised: 31 October 2012 - Accepted: 6 November 2012 - Published: 16 November 2012

\begin{abstract}
The uncertainties associated with the wet removal of aerosols entrained above convective cloud bases are investigated in a global aerosol-climate model (ECHAM5-HAM) under a set of limiting assumptions for the wet removal of the entrained aerosols. The limiting assumptions for the wet removal of entrained aerosols are negligible scavenging and vigorous scavenging (either through activation, with sizedependent impaction scavenging, or with the prescribed fractions of the standard model). To facilitate this process-based study, an explicit representation of cloud-droplet-borne and ice-crystal-borne aerosol mass and number, for the purpose of wet removal, is introduced into the ECHAM5-HAM model. This replaces and is compared with the prescribed cloud-droplet-borne and ice-crystal-borne aerosol fraction scavenging scheme of the standard model.

A $20 \%$ to $35 \%$ uncertainty in simulated global, annual mean aerosol mass burdens and optical depth (AOD) is attributed to different assumptions for the wet removal of aerosols entrained above convective cloud bases. Assumptions about the removal of aerosols entrained above convective cloud bases control modeled upper tropospheric aerosol concentrations by as much as one order of magnitude.

Simulated aerosols entrained above convective cloud bases contribute $20 \%$ to $50 \%$ of modeled global, annual mean aerosol mass convective wet deposition (about $5 \%$ to $10 \%$ of the total dry and wet deposition), depending on the aerosol species, when including wet scavenging of those entrained aerosols (either by activation, size-dependent impaction, or with the prescribed fraction scheme). Among the simulations, the prescribed fraction and size-dependent impaction
\end{abstract}

schemes yield the largest global, annual mean aerosol mass convective wet deposition (by about two-fold). However, the prescribed fraction scheme has more vigorous convective mixed-phase wet removal (by two to five-fold relative to the size-dependent impaction scheme) since nearly all entrained accumulation and coarse mode aerosols are assumed to be cloud-droplet borne or ice-crystal borne, and evaporation due to the Bergeron-Findeisen process is neglected.

The simulated convective wet scavenging of entrained accumulation and coarse mode aerosols has feedbacks on new particle formation and the number of Aitken mode aerosols, which control stratiform and convective cloud droplet number concentrations and yield precipitation changes in the ECHAM5-HAM model. However, the geographic distribution of aerosol annual mean convective wet deposition change in the model is driven by changes to the assumptions regarding the scavenging of aerosols entrained above cloud bases rather than by precipitation changes, except for sea salt deposition in the tropics. Uncertainty in the seasonal, regional cycles of AOD due to assumptions about entrained aerosol wet scavenging is similar in magnitude to the estimated error in the AOD retrievals.

The uncertainty in aerosol concentrations, burdens, and AOD attributed to different assumptions for the wet scavenging of aerosols entrained above convective cloud bases in a global model motivates the ongoing need to better understand and model the activation and impaction processes that aerosols undergo after entrainment into convective updrafts. 


\section{Introduction}

Aerosols play an important role in the climate system by influencing the Earth's radiation budget, directly by scattering and absorbing radiation, and indirectly by modifying cloud properties (Twomey, 1991; Charlson et al., 1992). Aerosols also have important impacts on global air quality (van Donkelaar et al., 2010) and human health (Dockery et al., 1993). As a result, the prediction of three-dimensional aerosol distributions is important in both global climate and air quality models. These distributions are strongly influenced by convective transport and wet scavenging in convective clouds. However, the aerosol-cloud interactions involving convective clouds are complex and in global models must be parameterized since convective clouds occur at scales smaller than the typical model grid box size. As a result, the representation of convective processes remains a major uncertainty for aerosol prediction in global models despite ongoing research efforts (Nober et al., 2003; Randall et al., 2003; Menon and Rotstayn, 2006; Lohmann, 2008; Tost et al., 2010; Morales et al., 2011).

Aerosols influence convective clouds since they act as cloud condensation and ice nuclei, and also by the semidirect effect since they absorb radiation, which produces local heating that contributes to cloud dissipation and changes in the atmospheric stability (Hansen et al., 1997; Ackerman et al., 2000). Conversely, convective clouds also influence three-dimensional aerosol distributions by cloud processing and wet scavenging (Engström et al., 2008), which is the focus of this study. Textor et al. (2006) found that the predicted contribution of convective clouds to global and annual mean aerosol wet deposition ranged between $10 \%$ and $90 \%$ when comparing a suite of global models. Thus, there is no clear consensus on how much convective clouds contribute to aerosol removal from the atmosphere.

Aerosols are susceptible to removal by convective precipitation when they become cloud-droplet borne and ice-crystal borne. Global models often assume fixed values to represent the fraction of cloud-droplet-borne and ice-crystal-borne aerosol in convective updrafts (Liu et al., 2001; Stier et al., 2005; Donner et al., 2011; Fang et al., 2011). The fraction of aerosol mass in the updrafts that is cloud-droplet borne is typically assumed to be near unity for accumulation and coarse mode aerosols in liquid convective clouds. However, for the nucleation and Aitken modes, and for all aerosols in mixed-phase and ice clouds, these assumptions about the cloud-droplet-borne and ice-crystal-borne aerosol fractions vary considerably between models (Liu et al., 2001; Stier et al., 2005). It is unclear how to best represent these fractions with respect to the aerosols that are entrained above convective cloud bases in global models.

Aerosols enter cloud droplets at convective cloud base where they may activate to form cloud droplets. Adiabatic activation parameterizations can accurately simulate the number of activated aerosols at convective cloud base (in as much as the model parameterizations correctly predict cloud updraft velocities) (Meskhidze et al., 2005). However, aerosols also entrain into convective updrafts above cloud base and can become susceptible to wet removal either through activation or collisions with existing cloud hydrometeors. It is unclear how to best represent the associated state of these entrained aerosols as either interstitial, cloud-droplet borne, or ice-crystal borne for the purposes of wet scavenging. To our knowledge, no previous global modeling study has quantified the potential contribution of aerosols entrained above convective cloud bases to the predicted aerosol wet removal under a set of limiting assumptions for the possible activation and collision processes that the entrained aerosols may undergo in the convective updrafts. Examining the contribution of entrained aerosols to wet removal and the associated uncertainty in predicted aerosol concentrations, burdens and optical depth in a global climate model related to wet removal of entrained aerosols is the focus of this study.

Previous studies have shown that assumptions related to the activation of aerosols entrained above cloud bases strongly impact the predicted cloud droplet and ice crystal number concentrations for deep convective clouds. Fridlind et al. (2004) found that the modeled number of ice crystals/cloud droplets in upper cloud regions was enhanced about an order of magnitude and in better agreement with aircraft observations from the CRYSTAL-FACE campaign in Florida when aerosols entrained above cloud base were assumed to activate. However, recent work has shown that observed ice crystal concentrations can be artificially high as a result of ice crystal shattering on aircraft measurement probes (Korolev et al., 2011). Other studies barely find evidence for activation of the aerosols entrained above cloud base (Freud et al., 2011). These uncertainties motivate our current study to put bounds on the potential contribution of entrained aerosols to predicted global aerosol wet removal.

The goals of this study are five-fold. (1) We quantify the uncertainty in predicted aerosol wet removal, concentrations, burdens and optical depth (AOD), which can be attributed to different assumptions about the wet scavenging of aerosols entrained above convective cloud bases in a global climate model. (2) To facilitate a process-based study, we introduce into the ECHAM5-HAM global aerosol-climate model a new parameterization for convective wet scavenging, which explicitly calculates the cloud-droplet-borne and ice-crystalborne aerosol mass and number concentrations for each aerosol mode based on a set of bounding assumptions about aerosol activation and impaction scavenging. This parameterization more closely couples the aerosol microphysics with the two-moment convective cloud microphysics of Lohmann (2008), and replaces the prescribed cloud-droplet-borne and ice-crystal-borne aerosol fractions used for wet scavenging in the standard model. (3) We evaluate and compare the predicted aerosol concentrations, burdens, and wet removal under the calculated fraction schemes relative to the prescribed fractions approach of the standard model. (4) We document 
the potential contribution of aerosols entrained above convective cloud base to predicted wet removal in a global model under bounding assumptions for the efficiency of impaction and activation scavenging. (5) We examine the coupling between the predicted aerosol burdens (and AOD) and precipitation for this set of sensitivity simulations from a climate perspective with both a global, annual and a regional, seasonal focus.

Although we use a state-of-the-art global climate model (GCM) for this study, a GCM does not resolve clouds. Particularly, for the case of convection, an ensemble of convective clouds at a variety of spatial scales is parameterized in each model grid box as a single entraining plume following the mass flux scheme of Tiedtke (1989). Further, the parameterization of convective precipitation (and hence wet scavenging) in global models is a notoriously challenging problem (Plant, 2010; Piriou et al., 2007; Randall et al., 2007; Arakawa, 2004). There is an ongoing need for better representation of convective cloud processes, and associated wet scavenging in global models, as our set of sensitivity simulations will indicate.

The following section gives a model description. Results are summarized in Sect. 3. We examine the contribution of aerosols entrained above cloud base to convective wet removal in the ECHAM5-HAM model, predicted aerosol deposition budgets, lifetimes, concentrations, burdens and AOD under our set of bounding assumptions. Our simulated results are compared with retrievals of global aerosol optical depth from a MODIS/MISR/AERONET compilation (van Donkelaar et al., 2010), a global precipitation data set from the Global Precipitation Climatology Project (Adler et al., 2003; Hoffman et al., 2009) and a suite of global cloud properties. We selected these comparisons to show that our simulations are reasonable in comparison to a set of global retrievals while highlighting the sensitivity of the predicted aerosol fields to uncertainties in the assumptions for convective wet scavenging of entrained aerosols.

\section{Model description and development}

The ECHAM5 model is a fifth generation atmospheric general circulation model (GCM) developed at the Max-Planck Institute for Meteorology (Roeckner et al., 2003). ECHAM5 evolved from the model of the European Centre for Medium Range Weather Forecasting (ECMWF). The model solves prognostic equations for vorticity, divergence, temperature and surface pressure using spherical harmonics with triangular truncation. The solar radiation scheme has 6 spectral bands (Cagnazzo et al., 2007) and the infrared has 16 spectral bands (Mlawer et al., 1997; Morcrette et al., 1998). Water vapor, cloud liquid water and ice are transported using a semi-Lagrangian scheme (Lin and Rood, 1996). Prognostic equations for stratiform cloud water and ice follow the two-moment cloud microphysics scheme of Lohmann et al.
(2007). The model includes the cirrus scheme of Lohmann and Kärcher (2002). Convective clouds, and convective transport are based on the mass-flux scheme of Tiedtke (1989) with modifications following Nordeng (1994).

For all simulations conducted in this study, we have implemented the two-moment convective cloud microphysics scheme described in detail in Lohmann (2008). This scheme predicts the liquid and ice water content, as well as the cloud droplet and ice crystal number concentrations for the convective clouds simulated within the context of the convective tracer transport scheme. An ensemble of convective clouds is represented as a single updraft plume within each grid box, allowing only one type of convection, either shallow, midlevel or deep. The convective cloud cover, $b^{\text {conv }}$, is obtained from the updraft mass flux $\left(\overline{F^{\text {up }}}\right)$

$b^{\text {conv }}=\frac{\overline{F^{\text {up }}}}{\rho \omega_{u}}$

where $\rho$ is the air density and $\omega_{u}$ is an assumed vertical velocity $\left(2 \mathrm{~m} \mathrm{~s}^{-1}\right)$. The convective microphysics scheme of Lohmann (2008) includes microphysical conversion rates for aerosol activation only at cloud base following a modified Lin and Leaitch (1997) scheme, autoconversion, heterogeneous contact and immersion freezing of cloud droplets, the Bergeron-Findeisen process, aggregation and accretion. For each model time-step, accretion of cloud droplets and ice crystals with rain and snow falling from grid boxes above is included through a preliminary updraft calculation that allows the amount of rain and snow produced to be saved, and subsequently used to calculate accretion for the final updraft calculation, as described in Lohmann (2008). Autoconversion is parameterized following Khairoutdinov and Kogan (2000), and depends on the cloud droplet number concentration and the liquid water content. The parameterization for aggregation follows Levkov et al. (1991).

Additionally, for this study, the GCM is coupled to the Hamburg Aerosol Model (HAM), which is described in detail in Stier et al. (2005). The aerosols are represented by seven log-normal modes, 4 soluble/internally mixed modes (nucleation (NS), Aitken (KS), accumulation (AS), and coarse (CS)) and 3 insoluble modes (Aitken (KI), accumulation (AI), and coarse (CI)). The simulated aerosol species are sulfate, black carbon, particulate organic matter, sea salt and dust. In-cloud formation of sulfate is parameterized for the stratiform clouds, and the resultant sulfate is attributed to the AS and CS modes. In-cloud formation of sulfate is not included for convective clouds. The count-median radius for each mode is calculated from the aerosol mass and number distributions in each mode. Aerosol mass and number are transferred between the modes by the processes of sulfuric acid condensation, and aerosol coagulation. All results presented in this study are from five-year free-running simulations, following a three months spin-up period, using climatological sea surface temperatures and sea ice extent for the year 2000. Aerosol emissions are taken from the AEROCOM 
database and are representative for the year 2000 (Dentener et al., 2006) except for sea salt and dust emissions, which are computed interactively as described in Stier et al. (2005). The simulations are conducted at T42 resolution (approximately $2.8^{\circ} \times 2.8^{\circ}$ grid spacing), with a vertical resolution of $19 \mathrm{lev}$ els from the surface to $10 \mathrm{hPa}$, and with a 20-min timestep.

The aerosol removal processes of sedimentation and dry deposition are described in detail in Stier et al. (2005). The stratiform size-dependent below-cloud and in-cloud aerosol scavenging schemes of Croft et al. (2009, 2010), and the convective below-cloud scavenging scheme of Stier et al. (2005) are employed for this study. Stratiform and convective below-cloud scavenging is parameterized to occur only in cloud-free grid boxes. Particularly for convective clouds, the prediction of below-cloud scavenging is not straightforward (due to precipitation potentially falling out of the clouds at many levels). Further, there may be below-cloud impaction scavenging that occurs in partly cloudy grid boxes when rain falls out of the side of a slanted rain shaft. The parameterization of the convective precipitating fraction for the GCM grid box has a key role to play and is not particularly well treated in GCMs since most GCMs parameterize this fraction with assumed fixed updraft velocities. In our model this parameterization yields negligible convective below-cloud scavenging relative to the below-cloud scavenging for stratiform clouds. However, this convective below-cloud scavenging parameterization was used for all simulations in this study since we wanted to focus on the in-cloud processes, and we did not wish to introduce a haphazard correction.

\subsection{Setup of convective in-cloud aerosol wet scavenging simulations}

Table 1 summarizes the setup for the five model simulations that were conducted for this study. All changes to the scavenging parameterizations are applied for shallow, mid-level and deep convection. The model is not re-tuned between any of the simulations. Further details about the scavenging parameterizations are provided below and in Appendix A.

The first simulation, PF_std, includes the convective in-cloud scavenging parameterization of the standard ECHAM5-HAM model as introduced by Stier et al. (2005). For this simulation, the fractions of aerosol mass and number that are cloud-droplet borne and ice-crystal borne in the convective updrafts for the purpose of wet removal are prescribed as a function of the aerosol mode and are independent of cloud temperature. These prescribed fractions, $R_{i}$, are given in Table 2. The prescribed fractions are applied at each vertical level to the in-updraft aerosol concentrations, which have been adjusted by entrainment and detrainment at each vertical level. As a result, this scavenging parameterization implicitly allows for aerosols that are entrained into the updraft above the cloud base to become cloud-droplet borne and ice-crystal borne, and susceptible to removal by precipitation formation.
Table 1. Wet scavenging scheme implemented for the aerosols entrained above convective cloud bases for the five simulations of this study. Note that for the aerosols entering at convective cloud base, all the calculated fraction $(\mathrm{CF})$ simulations allow activation scavenging coupled with the respective impaction scheme applied for the aerosols entrained above cloud base. The prescribed fraction (PF) simulation scavenges aerosols entering at convective cloud base with the same prescribed fractions as applied for the aerosols entrained above cloud base. Low and high efficiency refers to the collection efficiency for accumulation and coarse mode aerosol mass.

\begin{tabular}{llll}
\hline & Prescribed & \multicolumn{2}{c}{ Calculated Fractions } \\
\cline { 3 - 4 } & Fractions & Activation & Impaction \\
\hline PF_std & Yes & No & No \\
CF_base & No & No & No \\
CF_act & No & Yes & Yes (low efficiency) \\
CF_loimp & No & No & Yes (low efficiency) \\
CF_hiimp & No & No & Yes (high efficiency) \\
\hline
\end{tabular}

Table 2. Prescribed cloud-droplet-borne fractions as a function of aerosol mode implemented for the purposes of convective wet scavenging and used for the simulation PF_std. The same fractions are used for ice-crystal-borne fractions.

\begin{tabular}{lll}
\hline & $\begin{array}{l}\text { Soluble/ } \\
\text { Internally Mixed }\end{array}$ & $\begin{array}{l}\text { Insoluble/ } \\
\text { Externally Mixed }\end{array}$ \\
\hline Nucleation Mode & 0.2 & \\
Aitken Mode & 0.6 & 0.2 \\
Accumulation Mode & 0.99 & 0.4 \\
Coarse Mode & 0.99 & 0.4 \\
\hline
\end{tabular}

To facilitate this study, we introduce into the ECHAM5HAM model an explicit representation of the convective cloud-droplet-borne and ice-crystal-borne aerosol mass and number based on the convective cloud microphysics of Lohmann (2008). This scheme is used for the four remaining calculated scavenging fraction simulations in replacement of the prescribed fraction scheme. The considered microphysical processes are aerosol activation, aerosol-cloud droplet and aerosol-ice crystal collisions, heterogeneous contact and immersion freezing, Bergeron-Findeisen process, autoconversion, aggregation, and accretion. The four calculated fractions simulations more closely link the modeled cloud microphysics with the wet scavenging to calculate the cloud-droplet-borne and ice-crystal-borne aerosol mass and number for the purposes of aerosol wet removal. Appendix A contains a detailed description of the calculated fraction scavenging parameterization.

Simulation CF_loimp calculates the cloud-droplet-borne and ice-crystal-borne aerosol fractions for the purposes of wet scavenging assuming aerosol activation at cloud base only, coupled with prescribed collision kernels as a function 
of aerosol mode (Hoose et al., 2008) for collisions of all aerosols entrained above cloud base with cloud droplets and ice crystals. The Hoose et al. (2008) kernels were developed based on a flux model, which predicts a zero collision efficiency for collisions between coarse mode aerosols and cloud droplets or ice crystals. If sufficient coarse mode aerosols are entrained above cloud base and assumed not to activate, this Hoose et al. (2008) collision efficiency parameterization will strongly limit predicted aerosol mass wet removal since the majority of aerosol mass resides in the accumulation and coarse modes. While this impaction scavenging parameterization is of low efficiency for removal of aerosol mass considering the sum over all modes, this parameterization does remove aerosol mass in the nucleation and Aitken modes with relatively greater efficiency than for the accumulation and coarse modes.

Simulation CF_base assumes only aerosols entering at cloud base are susceptible to wet scavenging by aerosol activation at cloud base only and impaction using the Hoose et al. (2008) kernels. Contrary to simulation CF_base, in simulation CF_loimp aerosols entrained above cloud base are allowed to enter cloud droplets and ice crystals by collisions.

Simulation CF_hiimp is similar to simulation CF_loimp but replaces the Hoose et al. (2008) collision kernels with a size-dependent impaction parameterization for entrained aerosols colliding with cloud droplets and ice crystals based on the combined flux-trajectory model of Wang et al. (1978). Aerosol uptake into cloud droplets by activation is assumed to occur only at cloud base. The size-dependent impaction scavenging parameterization allows non-zero scavenging of entrained coarse mode aerosols. Thermophoretic effects for evaporating or growing cloud droplets are neglected, which could respectively increase or decrease the collision kernels. The kernels used for impaction scavenging are in look-up tables as a function of aerosol size, cloud droplet and ice crystal size and the cloud droplet and ice crystal number concentrations predicted by the model. For the aerosols entrained above cloud base, the wet count- or mass-median radius for the respective model layer is employed in look-up tables. This parameterization is described in detail in Croft et al. (2010) and their Fig. 1 shows these size-dependent kernels in comparison to those of Hoose et al. (2008), which are employed for the other calculated fractions simulations in this study.

Simulation CF_act assumes that soluble/internally mixed aerosols entrained above cloud base and larger than $25 \mathrm{~nm}$ in radius can participate in the activation scheme, and that all entrained and non-activated aerosols can collide with existing cloud hydrometeors via the Hoose et al. (2008) kernels. Cloud droplet detrainment is allowed at all model levels above cloud base. Simulation CF_act allows more vigorous uptake of entrained accumulation and coarse mode aerosols into cloud droplets and ice crystals for the purposes of wet scavenging than simulation CF_loimp.
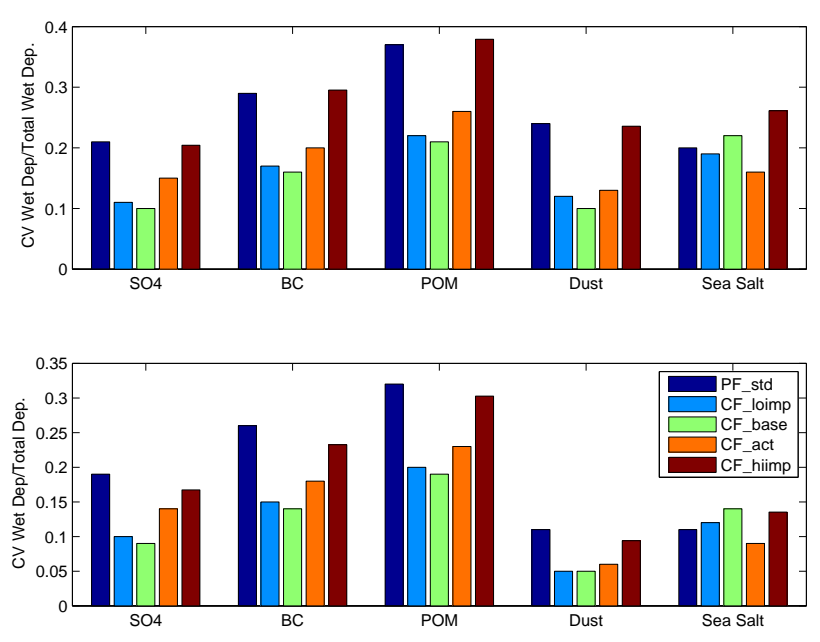

Fig. 1. The annual and global mean convective wet deposition relative to the total (stratiform and convective) wet deposition of aerosol mass (top panel), and relative to the total deposition of aerosol mass (bottom panel) for each aerosol species of the ECHAM5-HAM model: sulfate (SO4), black carbon (BC), particulate organic matter (POM), dust and sea salt, and for each of the five simulations of this study. Simulations are described in Table 1.

\section{Discussion}

\subsection{Contribution of aerosols entrained above convective cloud bases to global mean aerosol wet removal}

In this section, we consider the contribution of aerosols entrained above convective cloud bases to simulated global, annual wet removal in the aerosol-climate model ECHAM5HAM under a set of assumptions for aerosol uptake into cloud droplets and ice crystals for the purpose of wet removal. The introduction of an explicit representation of cloud-droplet-borne and ice-crystal-borne aerosol mass and number in the model allows us to extend our analysis to a process-based investigation of the influence of a set of limiting assumptions about activation and impaction scavenging on predicted wet removal.

Table 3 allows us to examine the contribution of aerosols entrained above convective cloud base to annual and global mean aerosol wet removal. This table contains the global, annual mean mass deposition budgets for the five aerosol species of the ECHAM5-HAM model and for the five simulations of this study. In interpreting these mass budgets, we keep in mind that the wet removal of the accumulation and coarse modes dominates the global mean mass wet deposition budgets since these modes contain the majority of the global aerosol mass. The two calculated fraction simulations that allow aerosol activation at cloud base only, and with no wet scavenging of entrained coarse mode aerosols (CF_loimp and CF_base) have the lowest convective wet deposition for each aerosol species. Further, the entrained accumulation 
mode aerosols are in the Greenfield gap size range (radius about $0.1 \mu \mathrm{m}$ ) (Greenfield, 1957), which is least vigorously scavenged by collisions, and not allowed to activate for simulations CF_loimp and CF_base. Simulations PF_std, CF_act and $\mathrm{CF}$ hiimp have relatively greater global, annual mean convective wet deposition. This additional wet removal is attributed to those aerosols that entrain and are scavenged above convective cloud bases. Thus, we estimate that a considerable fraction, between $20 \%$ to $50 \%$ of the predicted annual and global mean aerosol convective wet removal for simulations PF_std, CF_act and CF_hiimp can be attributed to wet scavenging of those aerosols entrained above cloud base. The behavior for sea salt is different and will be discussed further in Sect. 3.5 with consideration to precipitation changes in the model.

Table 3 also shows that convective wet scavenging of aerosol mass in mixed-phase clouds is lower by a factor of two to five for the calculated fractions simulations relative to simulation PF_std. This reflects the Bergeron-Findeisen process, which releases aerosols from cloud droplets (and from potential wet removal) as cloud droplets evaporate during cloud glaciation. This aerosol release due to evaporation makes removal less efficient and is included for the calculated fraction simulations, but not simulation PF_std. Thus, simulation PF_std should be regarded as giving an upper limit on the aerosol wet removal in mixed-phase clouds. Likewise for ice clouds, there is one order of magnitude lower convective wet scavenging for the calculated fractions simulations relative to PF_std, although this scavenging contributes considerably less to global wet deposition than for the mixedphase clouds.

In our model, the Bergeron-Findeisen process is parameterized such that all cloud droplets evaporate completely when a fixed minimum ice water content is exceeded. However, Korolev (2007) has shown that the Bergeron-Findeisen process (BFP) does not always proceed in a fixed manner. Engström et al. (2008) also show in a modeling study that this process is most efficient at higher altitudes above $8 \mathrm{~km}$, whereas droplet evaporation near to the freezing level is more often associated with the entrainment of dry air. Thus, the effect of the Bergeron-Findeisen process found here represents an upper limit on the release of aerosols by cloud droplet evaporation as clouds glaciate and a lower limit on the wet removal since the BFP can be less efficient than parameterized in the ECHAM5-HAM model. Nevertheless, our results demonstrate that under these limits, the aerosol release due to evaporation of cloud droplets has a non-negligible effect on the predicted wet removal attributed to mixed-phase and ice clouds. Further, a single fixed prescribed fraction applied over the entire temperature range for each aerosol mode is not able to capture any of these separate effects for mixedphase versus liquid clouds.

Among the four calculated fraction simulations, $\mathrm{CF}_{-}$act has the largest mixed-phase wet scavenging, by up to a factor of two. This is expected since allowing activation of
Table 3. Global and annual mean deposition budgets for sulfate, black carbon, particulate organic matter, dust and sea salt $\left(\mathrm{Tg} \mathrm{yr}^{-1}\right.$, except $\mathrm{Tg} \mathrm{S} \mathrm{yr}^{-1}$ for sulfate) for the five simulations presented in Table 1. Liquid refers to cloud temperatures warmer than $273 \mathrm{~K}$, mixed-phase refers to temperatures between $273 \mathrm{~K}$ and $238 \mathrm{~K}$, and ice refers to temperatures below $238 \mathrm{~K}$. ICS: in-cloud scavenging, BCS: below-cloud scavenging, Sed and Dry Dep: sedimentation and Dry Deposition.

\begin{tabular}{|c|c|c|c|c|c|}
\hline Sulfate & PF_std & CF_loimp & CF_base & CF_act & CF_hiimp \\
\hline \multicolumn{6}{|l|}{ Convective ICS } \\
\hline Liquid & 9.73 & 6.88 & 5.65 & 8.60 & 12.6 \\
\hline Mixed-Phase & 4.12 & 0.57 & 0.76 & 1.54 & 1.02 \\
\hline Ice & 0.02 & 0.0004 & 0.0004 & 0.0006 & 0.001 \\
\hline \multicolumn{6}{|l|}{ Stratiform ICS } \\
\hline Liquid & 27.8 & 29.9 & 30.6 & 31.0 & 27.6 \\
\hline Mixed-Phase & 11.5 & 14.3 & 11.9 & 13.0 & 13.2 \\
\hline Ice & 0.75 & 1.73 & 1.56 & 1.00 & 1.34 \\
\hline Stratiform BCS & 13.0 & 13.6 & 13.9 & 11.8 & 10.9 \\
\hline Sed and Dry Dep & 4.48 & 4.19 & 4.13 & 4.00 & 3.81 \\
\hline \multicolumn{6}{|l|}{ Black Carbon } \\
\hline \multicolumn{6}{|l|}{ Convective ICS } \\
\hline Liquid & 1.23 & 1.04 & 0.93 & 1.12 & 1.89 \\
\hline Mixed-Phase & 0.76 & 0.12 & 0.16 & 0.30 & 0.18 \\
\hline Ice & 0.003 & 0.0002 & 0.0002 & 0.0002 & 0.0003 \\
\hline \multicolumn{6}{|l|}{ Stratiform ICS } \\
\hline Liquid & 2.52 & 2.86 & 2.97 & 3.01 & 2.55 \\
\hline Mixed-Phase & 0.85 & 1.29 & 1.25 & 1.14 & 1.14 \\
\hline Ice & 0.07 & 0.23 & 0.23 & 0.14 & 0.17 \\
\hline Stratiform BCS & 1.37 & 1.41 & 1.43 & 1.27 & 1.08 \\
\hline Sed and Dry Dep & 1.00 & 0.84 & 0.82 & 0.82 & 0.81 \\
\hline \multicolumn{6}{|c|}{ Particulate Organic Matter } \\
\hline \multicolumn{6}{|l|}{ Convective ICS } \\
\hline Liquid & 14.3 & 12.0 & 11.1 & 12.5 & 20.8 \\
\hline Mixed-Phase & 6.91 & 1.11 & 1.52 & 3.09 & 1.83 \\
\hline Ice & 0.02 & 0.001 & 0.0009 & 0.001 & 0.002 \\
\hline \multicolumn{6}{|l|}{ Stratiform ICS } \\
\hline Liquid & 20.9 & 23.9 & 25.0 & 25.5 & 20.2 \\
\hline Mixed-Phase & 4.83 & 8.66 & 8.23 & 7.18 & 7.07 \\
\hline Ice & 0.53 & 2.06 & 1.96 & 1.16 & 1.42 \\
\hline Stratiform BCS & 10.6 & 11.7 & 11.8 & 10.2 & 8.37 \\
\hline Sed and Dry Dep & 8.45 & 6.88 & 6.81 & 6.79 & 6.70 \\
\hline \multicolumn{6}{|l|}{ Dust } \\
\hline \multicolumn{6}{|l|}{ Convective ICS } \\
\hline Liquid & 34.4 & 32.3 & 27.4 & 35.1 & 57.9 \\
\hline Mixed-Phase & 31.6 & 2.99 & 4.08 & 9.15 & 8.13 \\
\hline Ice & 0.16 & 0.01 & 0.02 & 0.05 & 0.06 \\
\hline \multicolumn{6}{|l|}{ Stratiform ICS } \\
\hline Liquid & 26.8 & 41.6 & 42.5 & 43.0 & 29.3 \\
\hline Mixed-Phase & 15.2 & 27.7 & 26.4 & 23.7 & 21.7 \\
\hline Ice & 0.92 & 2.91 & 3.66 & 2.46 & 2.05 \\
\hline Stratiform BCS & 171 & 192 & 209 & 225 & 161 \\
\hline Sed and Dry Dep & 299 & 345 & 343 & 348 & 262 \\
\hline \multicolumn{6}{|l|}{ Sea Salt } \\
\hline \multicolumn{6}{|l|}{ Convective ICS } \\
\hline Liquid & 348 & 624 & 678 & 455 & 843 \\
\hline Mixed-Phase & 380 & 114 & 162 & 99.6 & 175 \\
\hline Ice & 0.07 & 0.0002 & 0.0004 & 0.01 & 0.002 \\
\hline \multicolumn{6}{|l|}{ Stratiform ICS } \\
\hline Liquid & 692 & 970 & 959 & 1050 & 895 \\
\hline Mixed-Phase & 432 & 694 & 687 & 706 & 664 \\
\hline Ice & 0.10 & 2.67 & 5.72 & 1.77 & 1.61 \\
\hline Stratiform BCS & 1830 & 1450 & 1390 & 1570 & 1320 \\
\hline Sed and Dry Dep & 2550 & 2370 & 2310 & 2410 & 2310 \\
\hline
\end{tabular}


Table 4. Global and annual mean stratiform vertically integrated cloud droplet number concentration $\left(\mathrm{N}_{d}\right)\left(10^{10} \mathrm{~m}^{-2}\right)$, liquid water path (LWP) $\left(\mathrm{kg} \mathrm{m}^{-2}\right.$ ), cloud cover (CC), and precipitation (total, stratiform, and convective). LWP retrievals are from SSM/I (Greenwald et al., 1993; Weng and Grody, 1994; Ferraro et al., 1996). Total cloud cover is from ISCCP (Rossow and Schiffer, 1999) and total precipitation is from the Global Precipitation DataSet (Adler et al., 2003). Retrievals of $\mathrm{N}_{d}$ are from ISCCP (Han et al., 1998). The five simulations are described in Table 1.

\begin{tabular}{lrrrrrr}
\hline & $N_{\mathrm{d}}$ & LWP & CC & Total Precip & Strat Precip & CV Precip \\
\hline Retrievals & 4 & $49-84$ & $62-67$ & $2.64-2.7$ & & \\
PF_std & 5.66 & 81.3 & 64.0 & 2.89 & 1.45 & 1.44 \\
CF_loimp & 4.70 & 63.7 & 60.5 & 2.89 & 1.20 & 1.69 \\
CF_base & 4.76 & 66.9 & 60.7 & 2.88 & 1.21 & 1.67 \\
CF_act & 5.40 & 80.6 & 63.7 & 2.85 & 1.40 & 1.45 \\
CF_hiimp & 4.59 & 63.9 & 60.8 & 2.89 & 1.21 & 1.68 \\
\hline
\end{tabular}

aerosols entrained above cloud base readily scavenges entrained accumulation mode aerosols, which are more abundant than coarse mode aerosols at the higher altitudes where tropical mixed-phase convective scavenging occurs. Simulations CF_loimp, CF_base and CF_hiimp scavenge those entrained accumulation mode aerosols only by collision processes, which are least efficient for this size range (Greenfield, 1957). Thus, assumptions about whether the entrained accumulation mode aerosols activate strongly influence the predicted wet deposition attributed to mixed-phase convective clouds in our model.

Table 3 shows that for all aerosol species in the model, scavenging in liquid convective clouds makes the dominant contribution to the total aerosol mass convective wet deposition. This contribution is $80 \%$ to $90 \%$ for the four calculated fractions simulations, and $50 \%$ to $70 \%$ for simulation PF_std, which has the most vigorous mixed-phase scavenging. The convective wet deposition of aerosol mass attributed to liquid clouds is largest for simulation CF_hiimp, by a factor of almost two relative to simulations CF_loimp and CF_base. This can be attributed to the more vigorous impaction scavenging of entrained coarse mode aerosols for simulation $\mathrm{CF}$ hiimp relative to $\mathrm{CF}$ _loimp and CF_base. Entrained coarse mode mass is expected to be greatest near the earth's surface where liquid clouds occur and thus is particularly relevant for scavenging in liquid clouds. Simulation $\mathrm{CF}_{-}$act is expected to have equally vigorous coarse mode scavenging in liquid clouds (by activation of entrained coarse mode aerosols) relative to CF_hiimp. However, there are differences in the annual, global mean convective precipitation, which contribute to the relatively lower wet deposition from liquid clouds for $\mathrm{CF}$ _act relative to $\mathrm{CF}$ _hiimp.

Table 4 shows the annual and global mean total precipitation and the convective and stratiform contributions. The annual and global mean convective precipitation is $15 \%$ less for simulations PF_std and CF_act relative to the remaining three calculated fraction simulations. These changes are statistically significant at the $99 \%$ confidence level. However, the global and annual mean precipitation from stratiform and convective clouds together remains constant between all simulations. Simulations PF_std and CF_act allow entrained coarse mode aerosols to become cloud-droplet borne as efficiently as simulation CF_hiimp. However, the $15 \%$ lower annual, global mean convective precipitation yields about $30 \%$ lower convective wet deposition attributed to liquid clouds for simulation PF_std relative to simulation $\mathrm{CF}$ hiimp. The precipitation changes in the model will be discussed further in Sect. 3.4. Table 4 shows that simulations CF_loimp, CF_base and CF_hiimp have similar annual, global mean convective precipitation. As a result, the differences of up to $50 \%$ in the global and annual mean convective wet removal attributed to liquid clouds between these simulations highlight the importance of the parameterization for entrained coarse mode aerosols to become cloud-droplet borne in liquid convective clouds.

Tables 3 and 4 also show that differences in mass deposition between the simulations are more strongly driven by changes to the entrained aerosol wet scavenging parameterization rather than by the precipitation differences between the simulations, except for sea salt. For example, simulation PF_std scavenges entrained aerosols more vigorously than simulations CF_loimp and CF_base, but has $15 \%$ lower global, annual precipitation. However, with the exception of sea salt, the wet removal is still $20 \%$ to $30 \%$ greater for simulation PF_std, despite the lower convective precipitation. The behavior is different for sea salt, which is more strongly influenced by precipitation changes. Annual and global mean sea salt emissions change by less than $2 \%$ between our simulations and are not a major driver of annual, global mean sea salt deposition changes. Geographic distributions of wet deposition will be examined further in this context in Sect. 3.5.

Table 3 shows that simulations with the lowest global, annual mean convective wet deposition due to less vigorous scavenging of entrained aerosols ( $\mathrm{CF}_{-}$loimp and $\mathrm{CF}_{-}$base) have greater global, annual mean total (in-cloud and belowcloud) stratiform wet deposition since more aerosol mass is available to the stratiform scavenging scheme. However, despite this balance between the global, annual mean convective and stratiform wet scavenging, reduced convective wet scavenging of entrained aerosols contributes to longer 
aerosol lifetimes in our model, which will be further examined in the Sect. 3.2.

Figure 1 shows the modeled global, annual mean fractional contribution of convective wet deposition to both total wet deposition and total deposition of aerosol mass. Convective wet deposition accounts for $10 \%$ to $40 \%$ of the total wet deposition and $5 \%$ to $30 \%$ of total deposition in our model, depending on the aerosol species and scavenging parameterization. Simulations PF_std and CF_hiimp have the greatest contribution of convective wet deposition to total deposition as a consequence of having the most vigorous scavenging of entrained aerosol mass. Aerosol mass deposition is controlled by removal of the accumulation and coarse modes, which contain the majority of aerosol mass. Among the calculated fraction simulations, the contribution of convective wet deposition to total deposition is strongly sensitive to the parameterization of impaction scavenging of aerosols entrained above convective cloud base. This ratio is $20 \%$ to $30 \%$ greater for simulation $\mathrm{CF}$ hiimp relative to simulations CF_loimp and CF_base, which allow no impaction scavenging of entrained coarse mode aerosols. Simulation CF_act allows activation of the entrained accumulation and coarse mode aerosols, but Fig. 1 shows that the predicted convective to total wet deposition fractions are quite similar to those fractions for CF_loimp and CF_base. The lower global, annual mean convective precipitation for simulation $\mathrm{CF}_{-}$act relative to the other calculated fraction simulations contributes to this result.

Figure 1 shows that carbonaceous aerosols have the largest convective to total wet deposition ratio due to their major source regions in the ECHAM5-HAM model being in the tropics where convective precipitation dominates over stratiform precipitation. Convective wet deposition makes the lowest fractional contribution to total deposition for dust in our model, less than $10 \%$ for all simulations. This can be attributed to the strong contribution of sedimentation and dry deposition to the modeled global and annual mean dust deposition. Dust is often emitted in locations with low annual mean precipitation. Also the majority of the modeled dust is emitted in the coarse mode, which sediments and dry deposits out more readily than fine mode emissions. Figure 1 shows slightly different trends for sea salt than for the other aerosol species. This difference is driven by the strong sensitivity of the sea salt wet deposition to the precipitation changes in the model.

\subsection{Uncertainty in simulated aerosol optical depth, mass burdens, and concentrations attributed to entrained aerosol convective wet scavenging parameterizations}

In the previous section, we demonstrated the strong contribution of entrained aerosols to the predicted aerosol convective wet scavenging. In this section we consider the uncertainty in aerosol burdens, concentrations and optical depth, which can be attributed to the convective wet removal parameterization for entrained aerosols. Table 5 shows the global and annual mean mass burdens and lifetimes for the five aerosol species and the aerosol optical depth (AOD). Simulations PF_std, CF_act and $\mathrm{CF}$ hiimp have the lowest burdens and lifetimes by about $20 \%$ to $30 \%$ relative to simulations CF_loimp and CF_base. This can be attributed to more vigorous convective wet scavenging of aerosols entrained above cloud base, and can be considered as a low estimate on the uncertainty related to entrained aerosol wet removal since simulations PF_std and $\mathrm{CF}_{-}$act have $15 \%$ lower global, annual mean convective precipitation than simulations $\mathrm{CF}_{\text {_loimp and }} \mathrm{CF}_{-}$base. This result demonstrates the strong sensitivity of aerosol burdens to the parameterization for the wet scavenging of aerosols entrained above convective cloud bases. There are major aerosol mass emissions of biomass burning aerosols and dust between $30^{\circ} \mathrm{N}$ and $30^{\circ} \mathrm{S}$, where convective precipitation dominates over stratiform precipitation. This contributes to the strong sensitivity of these aerosol burdens to convective wet scavenging parameterizations. Less efficient convective wet scavenging allows further transport before eventual removal by either stratiform or convective precipitation and contributes to enhanced aerosol lifetimes.

Figure 2 shows the geographic distribution of the AOD for the five simulations of this study and the retrieval from MODIS/MISR/AERONET data set compiled by van Donkelaar et al. (2010). The geographic distribution of AOD reflects the geographic distribution of the aerosol burdens, particularly for the accumulation and coarse modes. The global AOD is dominated by African dust emissions and anthropogenic emissions in the Eastern Asia and India regions. The transport of African dust to the Caribbean and South America appears to be overestimated by simulations $\mathrm{CF}_{-}$loimp, CF_base and $\mathrm{CF}_{-}$act relative to the retrieval. This occurs since simulations CF_loimp and CF_base do not vigorously scavenge aerosols entrained above cloud base. Simulation CF_act has more vigorous scavenging of those entrained accumulation and coarse mode aerosols by activation but lower global, annual convective precipitation, which limits the removal. The AOD over the African continent appears to be underestimated by all simulations, suggesting that the dust emissions could be too low in the model.

We have calculated the mean fractional biases (MFB) between the simulations and the retrievals.

$\operatorname{MFB}=\frac{1}{N} \sum_{i=1}^{N} \frac{\left(C_{\mathrm{m}}-C_{\mathrm{o}}\right)}{\left(C_{\mathrm{o}}+C_{\mathrm{m}}\right) / 2}$

where $C_{\mathrm{m}}$ is the model prediction, $C_{\mathrm{o}}$ is the observation/retrieval, and $N$ is the number of model-observation pairs (Boylan and Russell, 2006). The MFB is lowest for the simulations CF_loimp, CF_base and CF_act. However, given the number of processes involved, global models are susceptible to being correct for the wrong reasons. It remains inconclusive whether any of our five simulations is a superior 
Table 5. Global and annual mean aerosol mass burdens (Tg, except Tg S for sulfate), lifetimes (days) in brackets after the burdens, and aerosol optical depth (AOD) for the five simulations presented in Table 1. The five aerosol species are sulfate (SO4), black carbon (BC), particulate organic matter (POM), dust (DU), and sea salt (SS).

\begin{tabular}{lrrrrr}
\hline & PF_std & CF_loimp & CF_base & CF_act & CF_hiimp \\
\hline & & & & & \\
SO4 & $0.759(3.9)$ & $1.22(6.3)$ & $1.20(6.2)$ & $0.831(4.3)$ & $0.957(5.0)$ \\
BC & $0.119(5.6)$ & $0.186(8.8)$ & $0.207(9.8)$ & $0.146(6.9)$ & $0.152(7.2)$ \\
POM & $1.06(5.9)$ & $1.74(9.6)$ & $1.93(10.7)$ & $1.33(7.3)$ & $1.41(7.8)$ \\
DU & $6.44(4.1)$ & $9.95(5.7)$ & $9.48(5.3)$ & $8.94(4.8)$ & $6.51(4.4)$ \\
SS & $9.12(0.54)$ & $15.7(0.93)$ & $14.9(0.88)$ & $13.9(0.81)$ & $11.5(0.68)$ \\
\hline AOD & 0.112 & 0.176 & 0.171 & 0.146 & 0.130 \\
\hline
\end{tabular}
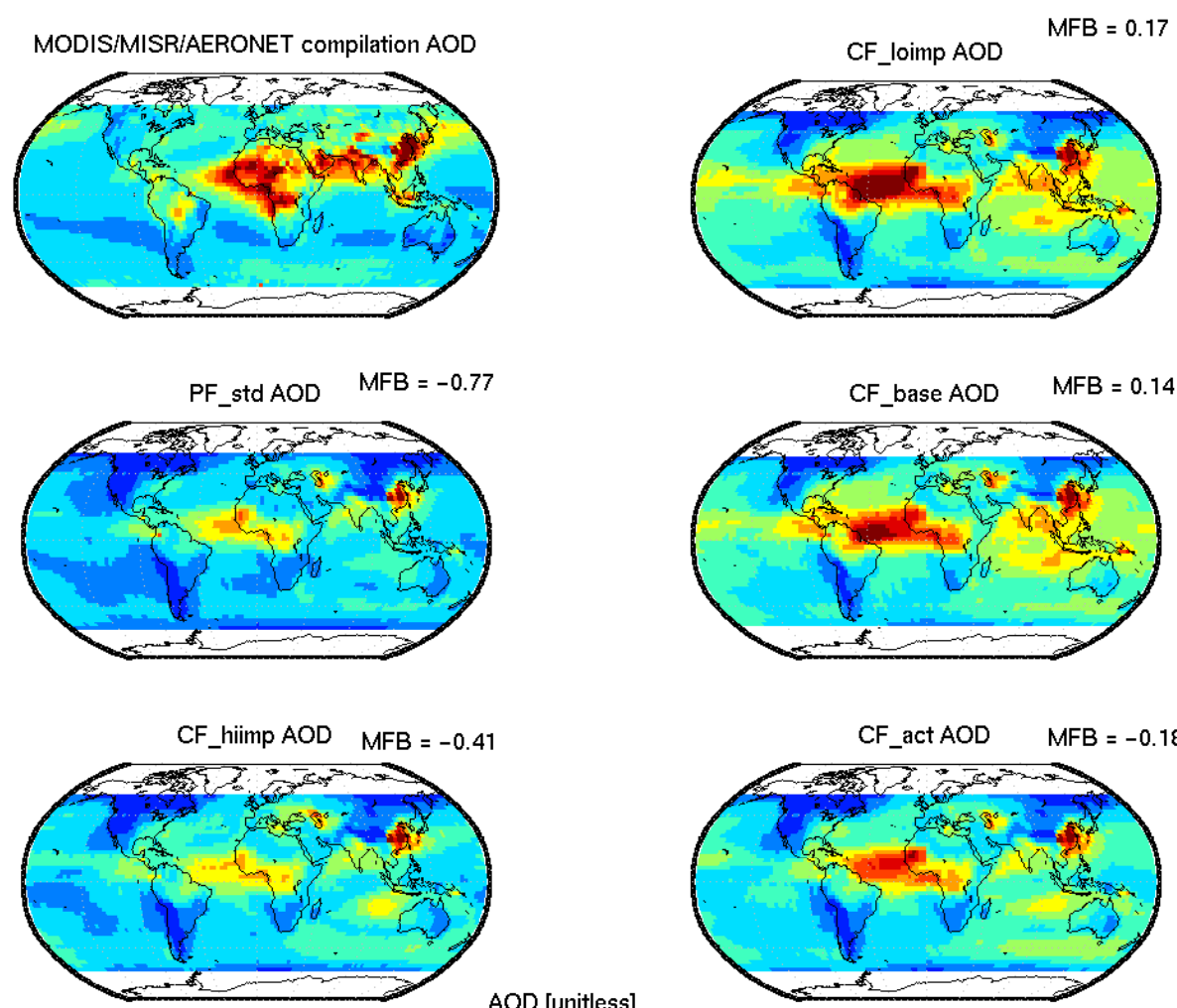

AOD [unitless]

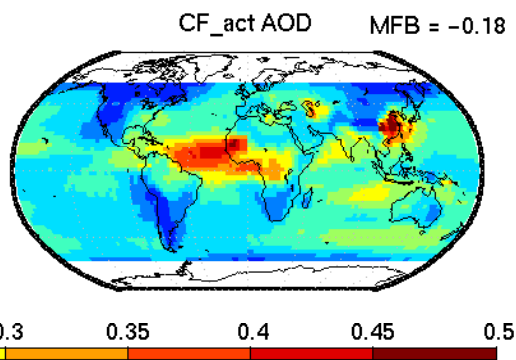

Fig. 2. The geographic distribution of annual mean aerosol optical depth (AOD) from the MODIS/MISR/AERONET compilation dataset of van Donkelaar et al. (2010) and for the simulations PF_std, CF_loimp, CF_base, CF_act, and CF_hiimp. The mean fractional bias (MFB) (Boylan and Russell, 2006) between the simulated and retrieved AOD is shown to the upper right of each panel. The simulations are described in Table 1.

parameterization. For example, the modeled AOD for simulations CF_loimp, CF_base, and $\mathrm{CF}_{\text {act }}$ act could agree more closely with the retrieved AOD due to an underestimation of emissions being matched with an undervigorous wet scavenging parameterization. Rather, our focus is to demonstrate and quantify the uncertainty in aerosol concentrations attributed to the convective wet scavenging parameterization for entrained aerosols. This is clearly evident in the geographic AOD differences of Fig. 2.

Table 5 shows that the global and annual mean AOD differs by $25 \%$ between simulations CF_loimp and CF_hiimp due to the impaction scavenging parameterization for aerosols entrained above convective cloud base. The global, annual mean AOD changes by $35 \%$ between simulations CF_base and PF_std under these limiting assumptions for the 
efficiency of wet removal of entrained aerosols. Recently, Ridley et al. (2012) examined African dust transport and deposition in the GEOS-Chem model and found that wet removal in that model appeared to be excessive across the Atlantic Ocean. Our results suggest that wet deposition and AOD in a global model are strongly sensitive to the amount of aerosol that is entrained into the convective updrafts and the assumptions for the removal of this aerosol. This is particularly relevant for the simulation of global mean AOD, which is controlled by emissions in tropical regions where convective precipitation dominates over stratiform precipitation.

Figure 3 shows the annual and zonal mean vertical profiles of soluble/internally mixed accumulation and Aitken mode mass concentration for simulation PF_std and the differences with the remaining four simulations. This figure demonstrates and quantifies the uncertainty in predicted upper tropospheric accumulation mode mass concentrations attributed to different assumptions for the wet scavenging of aerosols entrained above convective cloud bases. With negligible scavenging of accumulation mode aerosols entrained above convective cloud bases for simulation CF_loimp and CF_base relative to simulation PF_std, the accumulation mode mass concentrations for CF_loimp and CF_base are larger by up to one order of magnitude in the upper troposphere and a factor of two in the lower tropical troposphere. Simulations CF_act and CF_hiimp have upper tropospheric accumulation mode mass concentrations that are between a factor of two and five greater than for simulation PF_std. This arises due to the less vigorous scavenging in mixed-phase and ice clouds since the Bergeron-Findeisen process influences the scavenging for simulations CF_act and CF_hiimp, but not for simulation PF_std, as we discussed in examination of Table 3. Also, simulation CF_hiimp scavenges the entrained accumulation mode aerosols only by impaction, which is less vigorous for this size range (Greenfield gap). As result, among the calculated fraction simulations $\mathrm{CF}_{\text {act, }}$, which vigorously scavenges the accumulation mode by activation, has the lowest accumulation mode mass concentrations by a factor of five in the tropical mid-troposphere.

Figure 3 shows that the Aitken mode mass concentrations are lower for the four calculated fraction simulations than for simulation PF_std. The greatest difference is for simulation CF_base, which has upper tropospheric Aitken mass concentrations that are a factor of two lower relative to simulation PF_std. This difference is controlled by the increase in uppertropospheric aerosol surface area in the larger modes for simulation CF_base relative to PF_std. This suppresses nucleation of new particles and in turn reduces the resultant number of Aitken mode aerosols as the nucleation mode particles grow by coagulation. Simulation CF_base has wet removal only of those aerosols entraining at cloud base. Thus, this difference can not be attributed to more vigorous scavenging of the entrained Aitken mode aerosols for simulation CF_base relative to PF_std since CF_base scavenges only Aitken mode aerosols entering at cloud base. The Aitken mode difference is not as great for simulations CF_act and CF_hiimp, which have smaller increases in larger mode surface area in the middle and upper troposphere relative to PF_std. This figure demonstrates the control of entrained aerosol wet scavenging parameterizations on new particle formation and growth in a global model.

\subsection{Uncertainty in simulated aerosol number burdens attributed to entrained aerosol convective wet scavenging parameterizations}

In this section we quantify the uncertainty in predicted global, annual mean aerosol number burdens that can be attributed to assumptions about the wet scavenging of entrained aerosols. Table 6 shows the global, annual mean number burdens for the five simulations in this study. We find that differences in the convective wet scavenging parameterizations related to aerosols entrained above convective cloud bases strongly influence predicted aerosol number, both directly and indirectly. Less vigorous scavenging of entrained soluble accumulation and coarse mode aerosols (CF_loimp, CF_base relative to $\mathrm{CF}_{-}$act, $\mathrm{CF}$ hiimp, and PF_std) yields a $20 \%$ to $30 \%$ increase in the global, annual mean soluble/internally mixed accumulation and coarse mode number burdens.

There is more aerosol surface area in the accumulation and coarse modes for simulations CF_loimp and CF_base relative to $\mathrm{CF}_{\text {act }}$, CF_hiimp, and PF_std. This has important feedbacks on the formation of new aerosols in the model. The larger aerosol surface area provides a larger condensation sink for sulfuric acid and suppresses new particle formation. This contributes to a $10 \%$ to $25 \%$ reduction in the global, annual mean nucleation and soluble Aitken mode number burdens for simulations $\mathrm{CF}$ _loimp, $\mathrm{CF}$ _base relative to $\mathrm{PF}$ _std, CF_act and CF_hiimp. Simulation CF_hiimp also has more vigorous impaction scavenging of the Aitken mode relative to the other calculated fractions simulations.

The insoluble modes are scavenged by impaction scavenging alone, which is less vigorous for simulations CF_loimp, CF_base and CF_act and yields $50 \%$ larger global, annual mean insoluble accumulation and coarse mode number burdens relative to simulations PF_std and CF_hiimp. However, the insoluble mode number burdens are one to two orders of magnitude smaller than the soluble mode number burdens. The impacts of these scavenging-induced differences in the number burdens on the cloud properties and precipitation are examined further as a part of Sect. 3.4. Understanding the precipitation changes in our model is also useful towards interpreting the geographic distribution of wet deposition differences between the simulations, which are examined in Sect. 3.5.

Figure 4 shows the geographic distribution of the annual mean aerosol number burdens for the soluble Aitken, accumulation and coarse modes for the CF_loimp simulation and the relative difference with respect to the simulations PF_std 
a) Sol. Acc. Mode Mass [ug m-3 (PF std)

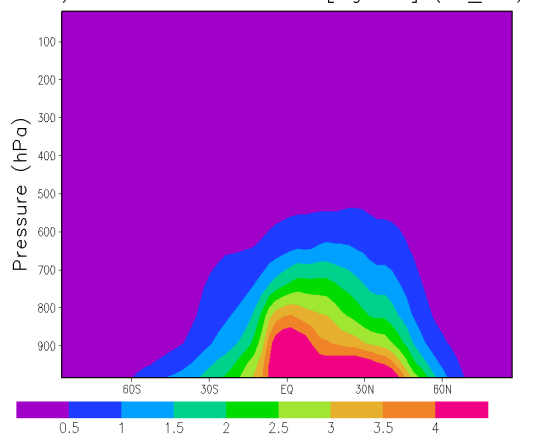

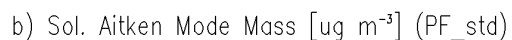

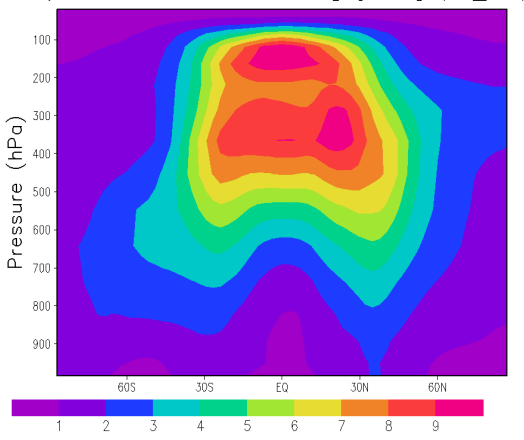

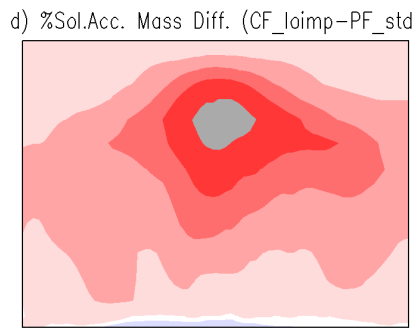
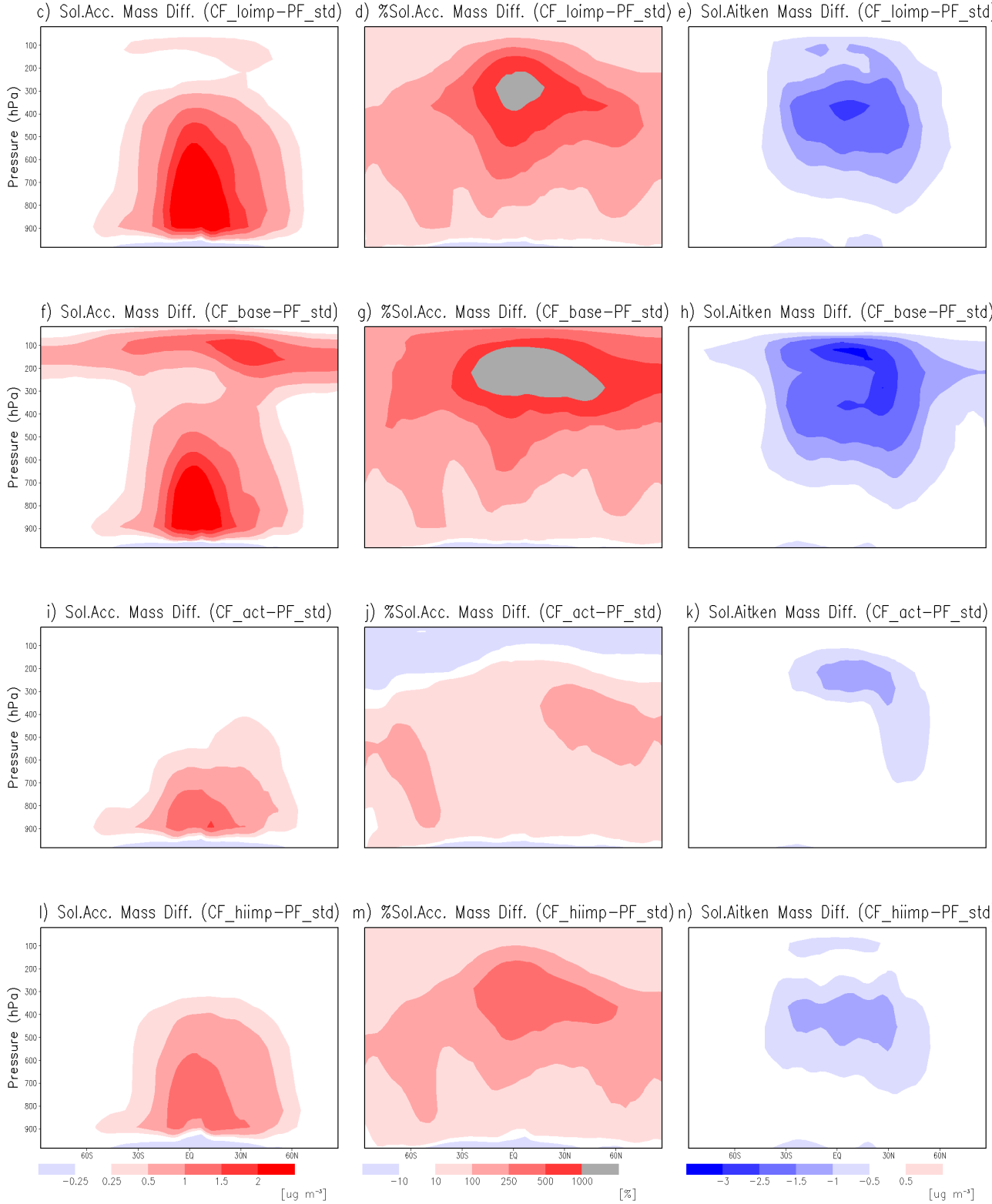

Fig. 3. The zonal and annual mean soluble/internally mixed (Sol.) accumulation (Acc.) and Aitken mode mass concentration at STP for the simulation PF_std (top panels), and the difference of the four calculated scavenging fractions simulations with respect to simulation PF_std (remaining left and right side panels). The percent difference in accumulation mode mass concentration of the calculated fraction simulations with respect to simulation PF_std is shown in the center panels. All simulations are described in Table 1. 


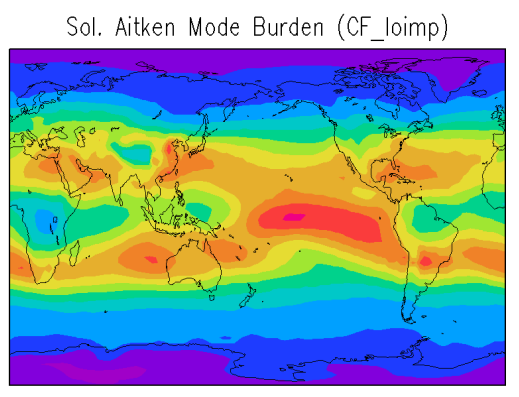

$\left[10^{10} \mathrm{~m}^{-2}\right]$

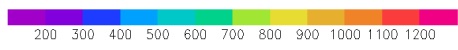

$\%$ Diff. Sol. Aitken Burden (PF_std-CF_loimp)
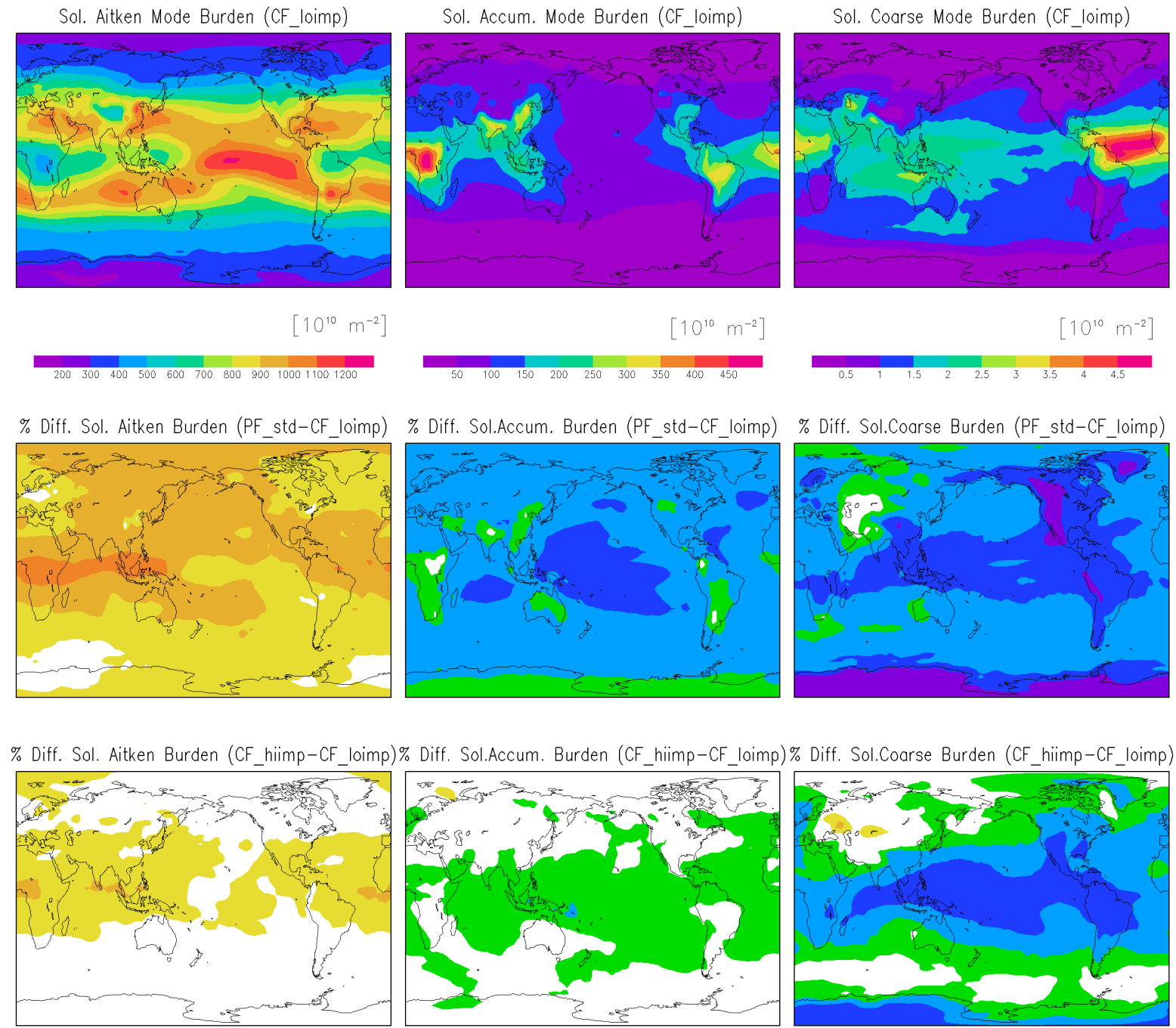

$[\%]$
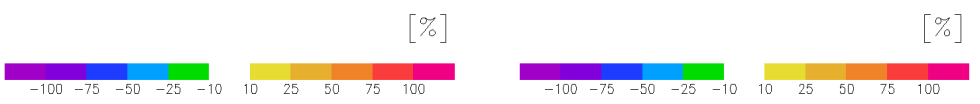

Fig. 4. The geographic distribution of annual mean soluble/internally mixed (Sol.) Aitken, accumulation (Accum.) and coarse mode number burdens for the simulation CF_loimp (top panels) and the percent difference of simulations PF_std and CF_hiimp with respect to CF_loimp (remaining panels). Simulations are described in Table 1.

and CF_hiimp. This figure highlights the geographic distribution of the uncertainty in aerosol number burdens associated with the parameterization for the convective wet removal of entrained aerosols. We chose to make the comparisons relative to simulation CF_loimp since comparing directly with simulation CF_hiimp will highlight the importance of the impaction scavenging parameterization for aerosols entrained above convective cloud base. The maxima for the accumulation and coarse mode number burdens occur in the tropics due to the major aerosol sources here for dust and biomass burning aerosols in Africa and South America and anthropogenic aerosol sources in East Asia and India. We also see the maxima in the Aitken mode in the subtropics associated with the strong source of nucleation mode aerosol in the upper tropical troposphere. These newly formed particles descend and grow by coagulation to form Aitken mode particles.

Comparing between simulations CF_loimp and CF_hiimp, Fig. 4 shows that including the scavenging of entrained coarse mode aerosols reduces the coarse mode burden between 50 to $75 \%$ near the equator. The accumulation mode burden is reduced between $10 \%$ and $25 \%$ in the same regions as a result of more vigorous scavenging of entrained accumulation mode aerosols for simulation CF hiimp relative to CF_loimp. However, the difference is smaller for the accumulation mode since those aerosols lie in the Greenfield 
Table 6. Global and annual mean aerosol number burdens $\left(10^{10}\right.$ $\mathrm{m}^{-2}$ ) for the five simulations presented in Table 1 and for the seven lognormal modes, NS: nucleation soluble, KS: Aitken soluble, AS: accumulation soluble, CS: coarse soluble, KI: Aitken insoluble, AI: accumulation insoluble, CI: coarse insoluble.

\begin{tabular}{rrrrrr}
\hline & PF_std & CF_loimp & CF_base & CF_act & CF_hiimp \\
\hline NS & 57900 & 53100 & 43900 & 57800 & 56700 \\
KS & 927 & 723 & 677 & 845 & 798 \\
AS & 64.2 & 101 & 102 & 72.8 & 89.4 \\
CS & 0.726 & 1.34 & 1.32 & 1.02 & 0.814 \\
KI & 7.64 & 8.08 & 8.12 & 7.96 & 7.42 \\
AI & 0.103 & 0.150 & 0.154 & 0.163 & 0.136 \\
CI & 0.166 & 0.248 & 0.242 & 0.248 & 0.173 \\
\hline
\end{tabular}

gap size range, which has limited scavenging by collision processes for both simulations. While the entrained coarse mode aerosols are not wet scavenged in simulation CF_loimp, CF_hiimp scavenges the coarse mode with a vigorous size-dependent impaction parameterization.

Simulation PF_std scavenges entrained accumulation and coarse mode aerosols more vigorously, assuming $99 \%$ of those aerosols are cloud-droplet borne and ice-crystal borne. As a result, Fig. 4 shows that the accumulation modes are more strongly reduced $(50 \%$ to $75 \%$ ) relative to simulation CF_loimp than for CF_hiimp. Those reductions extend further poleward for simulation PF_std, which unlike the calculated fraction simulations does not account for evaporation due to the Bergeron-Findeisen process for the purposes of the wet scavenging scheme. The reduced aerosol surface area for simulation PF_std relative to $\mathrm{CF}$ _loimp promotes increased formation of new particles, which grow into Aitken mode particles. As a result, this Aitken mode enhancement for simulation PF_std extends further poleward and is of greater magnitude (50\% to $75 \%$ in the tropics and $25 \%$ to $50 \%$ towards the Arctic relative to simulation CF_loimp) than for simulation $\mathrm{CF}$ hiimp ( $10 \%$ to $25 \%$ in the tropics) relative to $\mathrm{CF}$ _loimp. The geographic distribution of changes to the aerosol number burdens is useful towards understanding the geographic distribution of precipitation changes in the model, which is the focus of the next section.

\subsection{Influence of entrained aerosol wet scavenging on cloud properties and precipitation}

In Sect. 3.1, we noted that the global, annual mean convective and stratiform precipitation change between our five simulations, although the total precipitation is essentially constant. This section further examines the precipitation response in our model, which in turn contributes to the differences in aerosol wet removal between our simulations. Cloud properties and precipitation in the ECHAM5-HAM model respond to the scavenging-induced changes in number burdens. Among our five simulations, CF_loimp, CF_base and
CF_hiimp have the lowest global, annual mean Aitken mode number burdens (Table 6), which strongly controls and reduces the cloud droplet number concentration (CDNC) in the model since the activation scheme allows soluble aerosols larger than $25 \mathrm{~nm}$ and $35 \mathrm{~nm}$ to potentially activate for the convective and stratiform clouds, respectively.

Table 4 shows the annual and global mean stratifrom cloud properties. For stratiform clouds, the global and annual mean CDNC burden is lower by about $15 \%$ for simulations $\mathrm{CF}$ _loimp, $\mathrm{CF}$ _base and $\mathrm{CF}$ hiimp relative to PF_std and $\mathrm{CF}$ act. Likewise, for these same simulations relative to PF_std and $\mathrm{CF}_{-}$act, the convective CDNC is lower by as much as a factor of two in the annual and zonal mean in the tropical mid-troposphere (not shown).

Reduced CDNC promotes precipitation formation at lower altitudes in our model (Khairoutdinov and Kogan, 2000). However, whether those clouds produce more precipitation relative to clouds with greater CDNC depends on moisture availability and evaporation (Stevens and Feingold, 2009), which are difficult for global models to predict (Plant, 2010). Observations have shown that convective clouds forming in regions of greater pollution, tend to have greater CDNC, which delays the onset of precipitation (Freud and Rosenfeld, 2012). This can lead to clouds with greater vertical development, latent heat release at higher altitudes that promotes destabilization and more vigorous convection, and possibly more precipitation formation depending on moisture availability, but also possibly less precipitation if the clouds evaporate before the precipitation forms (Andreae et al., 2004). For our simulations, lower global and annual mean convective CDNC (CF_loimp, CF_base and CF_hiimp relative to PF_std, CF_act) is associated with greater convective rain production frequency at lower altitudes (not shown) and $15 \%$ greater global and annual mean convective precipitation as shown in Table 4 . The differences in convective rain production were statistically significant at the $99 \%$ confidence level. Simulations PF_std and CF_act have greater global, annual mean convective $\mathrm{CDNC}$, the frequency of rain production in the lower model levels in reduced, the onset of precipitation is delayed to higher altitudes, and the clouds evaporate before producing precipitation. This latter effect is similar to the effects discussed by Andreae et al. (2004) and Freud and Rosenfeld (2012), but in our model the global, annual mean result of less frequent precipitation in lower levels is cloud evaporation (not invigorated precipitation formation at higher altitudes) and hence lower global, annual mean convective precipitation.

The greater amount of convective rain production in lower altitudes in the model makes less moisture available for the stratiform clouds. As a result, Table 4 shows that the global, annual mean stratiform liquid water path is reduced by $20 \%$, stratiform cloud cover by $5 \%$ and stratiform precipitation by $15 \%$ for simulations CF_loimp, CF_base and CF_hiimp relative to $\mathrm{PF} \_$std, $\mathrm{CF} \_$act. The global, annual mean evaporation from the surface in our atmosphere-only model with 

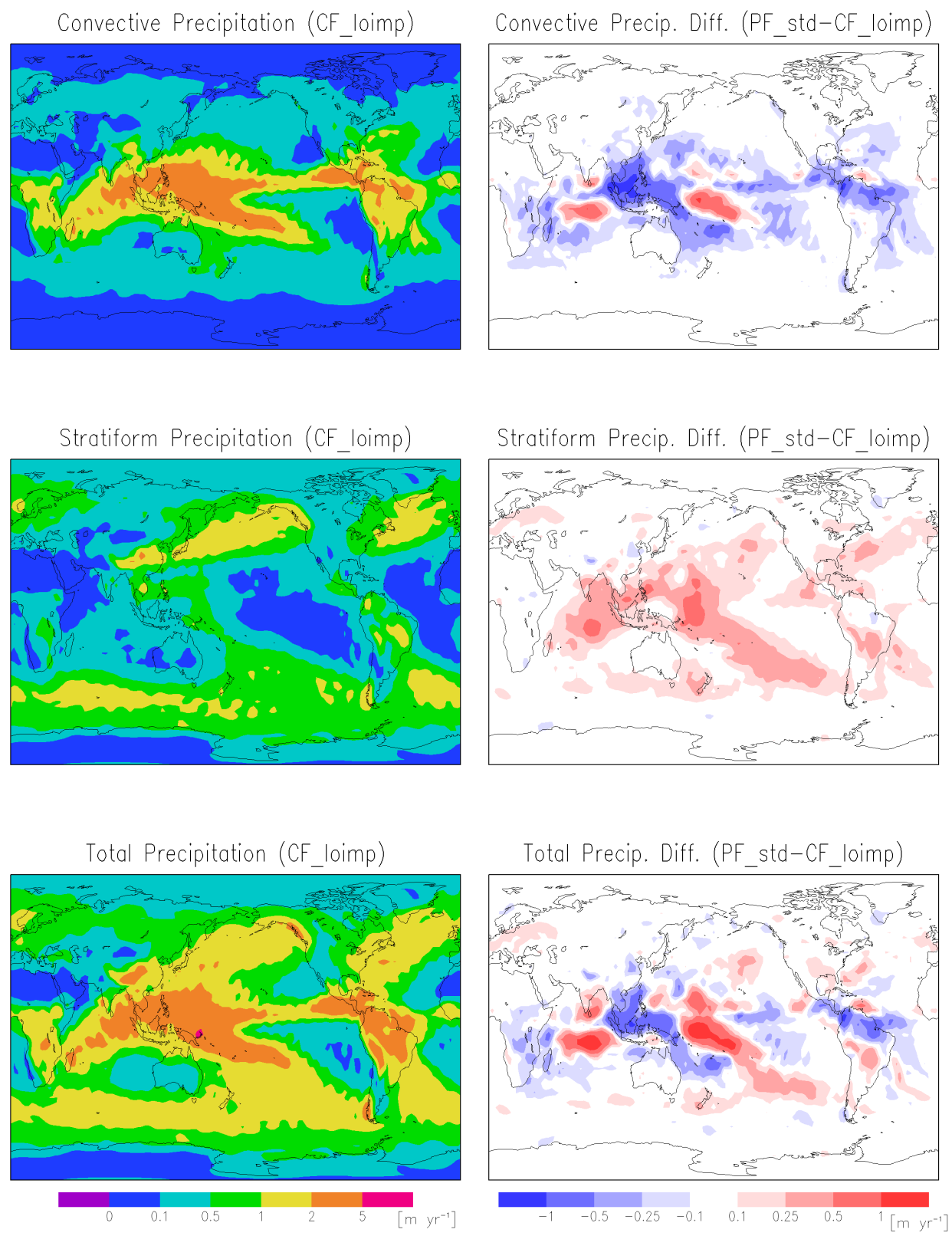

Fig. 5. The geographic distribution of annual mean convective, stratiform and total precipitation for the simulation CF_loimp (left panels) and the difference of simulation PF_std with respect to CF_loimp (right panels). Simulations are described in Table 1.

prescribed sea surface temperatures does not change by more than $1 \%$. Thus, changes to the annual and global mean convective precipitation are balanced by opposing changes to the stratiform precipitation. This precipitation response to perturbations in aerosol fields is associated with considerable uncertainty due to the dependency on moisture availability and evaporation. Nevertheless, simulated global stratiform cloud properties shown in Table 4 are within $10 \%$ of the global and annual mean retrievals.

Figure 5 shows the geographic distribution of the convective, stratiform and total precipitation for simulation
CF_loimp and the difference between simulations CF_loimp and PF_std. Convective precipitation has maxima between $30^{\circ} \mathrm{N}$ and $30^{\circ} \mathrm{S}$, whereas stratiform precipitation has maxima in the midlatitude storm tracks. The total precipitation maxima follow the same pattern as for the convective precipitation. The geographic distribution of the decrease in convective precipitation for simulation PF_std relative to CF_loimp generally follows the same geographic pattern as for the increase in the Aitken mode number burdens shown in Fig. 4, which strongly controls CDNC and in turn precipitation. In our model, increased Aitken mode number burdens are 

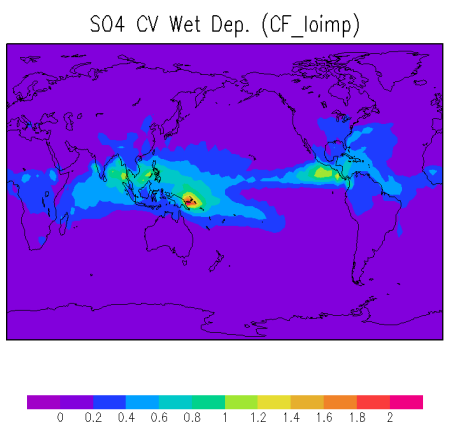

[kg hectare-1]
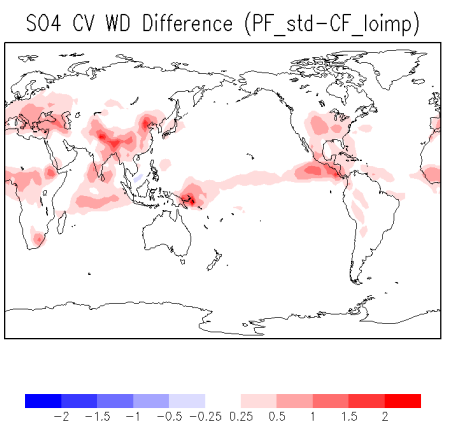

[kg hectare- $\left.{ }^{-1}\right]$

SS CV Wet Dep. (CF_loimp)
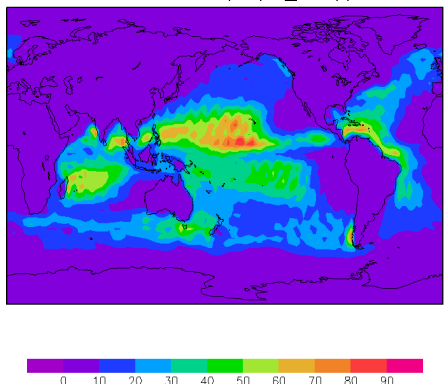

Tko hectore-17
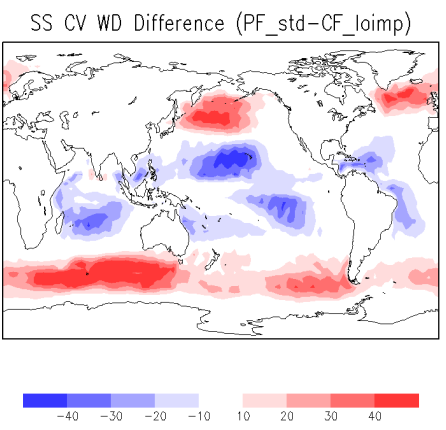

[kg hectore-1]

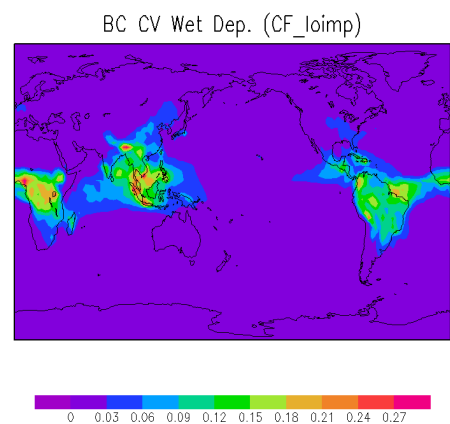

[kg hectore-1]
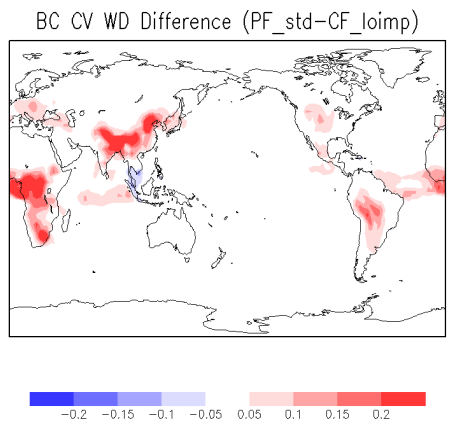

[kg hectare-1]

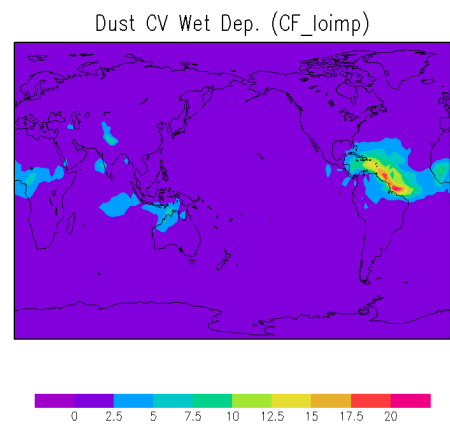

[kg hectare-1]
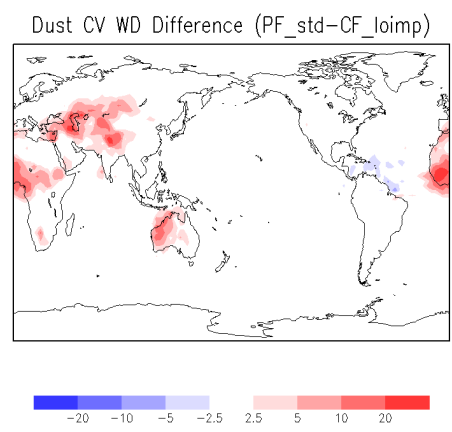

[kg hectore-1]

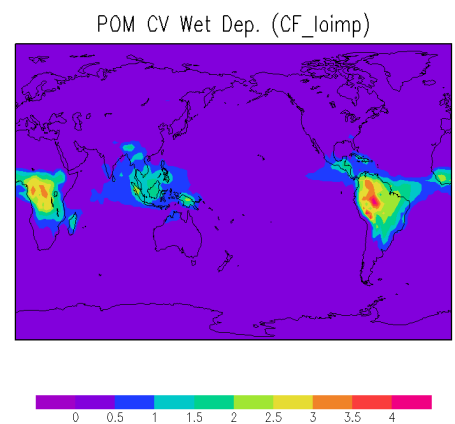

[kg hectare-1]
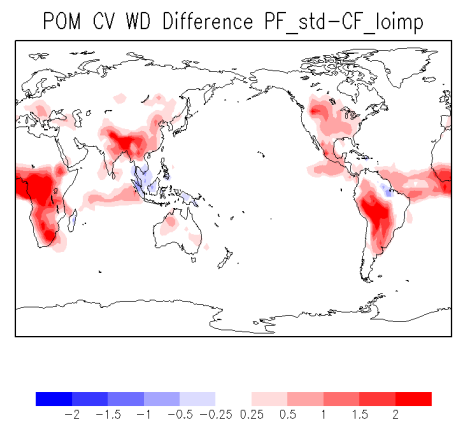

[kg hectare $\left.{ }^{-1}\right]$

Fig. 6. The geographic distribution of annual mean convective wet deposition (CV Wet Dep.) for the simulation CF_loimp and the difference of simulation PF_std with respect to CF_loimp for sulfate $\left(\mathrm{SO}_{4}\right)$, black carbon (BC), particulate organic matter (POM), sea salt (SS) and dust. Simulations are described in Table 1. 
associated with reduced annual, global mean precipitation from convective clouds. These regions of greatest increase in the Aitken mode number burdens are also coincident with the convective precipitation maxima. This is particularly evident in the western Pacific. Closer to the dateline, the Aitken mode number increase is less in magnitude, and this region is associated with an increase in convective precipitation. Many of these precipitation changes are over the ocean and there is the possibility that changing sea salt emissions could also influence the precipitation between our simulations. There are regional increases in sea salt emissions in the tropics of about $10 \%$ for simulation PF_std relative to CF_loimp (not shown), which could contribute to reductions in convective precipitation, but the sea salt burden in reduced by as much as $50 \%$ in these regions due to the more vigorous scavenging parameterization for simulation $\mathrm{PF} \_$std relative to $\mathrm{CF}$ _loimp. Indeed, the aerosol and precipitation fields are closely coupled, but the trigger for the precipitation response between our simulations is the convective wet scavenging differences between our simulations. The stratiform precipitation is generally increased in response to these decreases in convective precipitation and frequency in the tropics and along storm tracks, although the changes are not exactly coincident with the changes in the convective precipitation. These changes in convective precipitation will be used to interpret the changes to the geographic distribution of convective wet deposition between our simulations, which is the focus of the next section.

\subsection{Uncertainty in the simulated geographic distribution of aerosol wet deposition associated with entrained aerosol wet scavenging parameterizations}

Figure 6 shows the geographic distribution of annual mean convective wet deposition in the model. The maxima for the convective wet deposition are located by the interplay between the maxima for the aerosol emissions for each species and the convective precipitation maxima. However, the two main drivers for convective wet deposition changes between our simulations are the changing wet scavenging parameterization and the precipitation changes. The geographic distribution of simulated convective wet deposition change between our simulations is generally driven by changes to the parameterization for the wet scavenging of aerosols entrained above cloud bases, rather than by the precipitation change between our simulations. Figure 5 shows that the convective precipitation is generally decreased across the tropics for simulation PF_std relative to $\mathrm{CF}_{-}$loimp. Despite this reduction in precipitation, the wet deposition change is characterized by increases by as much as a factor of two. Thus, the convective wet deposition change and the convective precipitation change are anti-correlated, particularly close to the source regions when aerosols entrained above cloud base are more vigorously wet scavenged in simulation PF_std relative to CF_loimp.

Sea salt deposition in the tropics has a different response. The geographic distribution of changes in the sea-salt convective wet deposition in the tropics, shown in Fig. 6, is positively correlated with the geographic distribution of the tropical convective precipitation changes, shown in Fig. 5. Sea salt wet deposition for simulation PF_std relative to CF_loimp is reduced in the tropics with nearly the same geographic pattern as for the reduction in convective precipitation, despite the more vigorous scavenging of entrained aerosol mass for simulation PF_std relative to CF_loimp. Sea salt mass concentrations decay rapidly with altitude and the majority of sea salt mass activates readily at cloud base. As a result, sea salt mass deposition is less sensitive to changes in the assumptions about wet scavenging of sea salt entrained above cloud base, and relatively more sensitive to the precipitation changes in our model. The main driver of sea salt wet deposition change in the tropics for our simulations is the precipitation changes, as opposed to the wet scavenging parameterization for entrained aerosols. Sea salt emission changes are not a major driver of deposition changes between these simulations since sea salt emissions in the tropics are regionally greater by about $10 \%$ for simulation PF_std relative to CF_loimp, whereas convective wet deposition changes in the opposite direction between these simulations. Table 3 shows a similar response in that, the global, annual mean sea salt convective deposition is positively correlated with the global, annual mean convective precipitation between our five simulations. Figure 6 shows that at the higher latitudes (where there is relatively less convective precipitation), changes to the parameterization for the scavenging of entrained aerosols become the main driver for sea salt wet deposition changes. At these higher latitudes, more vigorous scavenging of entrained aerosols for simulation PF_std yields more vigorous wet deposition relative to simulation CF_loimp.

\subsection{Uncertainty in the simulated seasonal and regional AOD and precipitation associated with entrained aerosol wet scavenging parameterizations}

In many regions of the world, AOD has a strong seasonal cycle, as does precipitation. In this section, we consider the uncertainty in the seasonal and regional AOD attributed to assumptions about the scavenging of aerosol entrained above cloud bases with consideration to the seasonal cycle of precipitation. We chose to make this comparison to focus on the climatic relevance of assumptions for the wet scavenging of aerosol entrained above convective cloud bases. Figure 7 shows the seasonal cycle of AOD and precipitation for the five simulations and for regional boxes over South America, North America, Africa, India, China, and the West Pacific. This figure also shows the regional and seasonal mean AOD from the 2001-2006 MISR/MODIS/AERONET data set of van Donkelaar et al. (2010) and the 1995-2005 

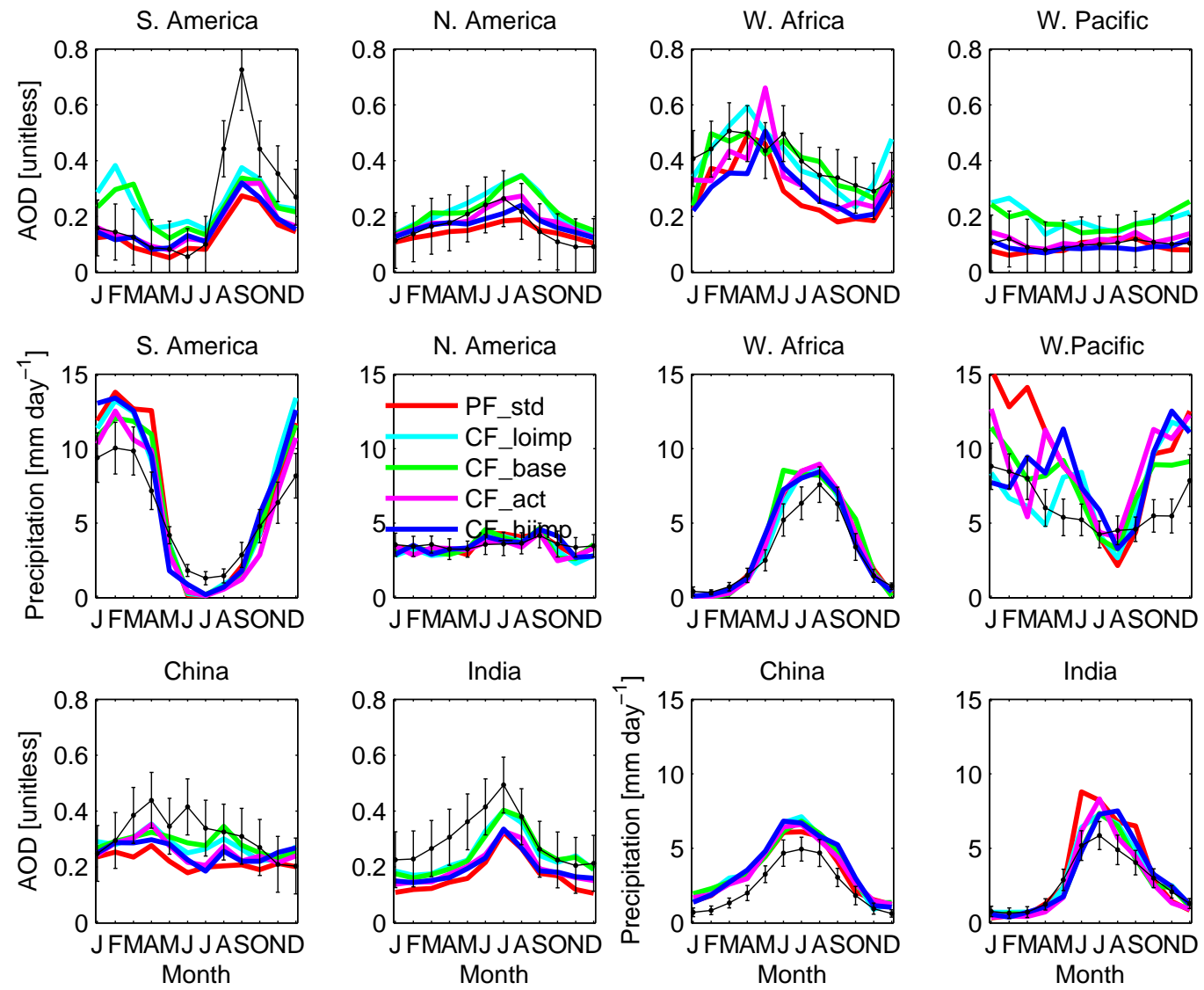

Fig. 7. Regional and monthly mean aerosol optical depth (AOD) and precipitation from the MODIS/MISR/AERONET retrieval of van Donkelaar et al. (2010) and the Global Precipitation Climatology Project retrieval (Adler et al., 2003; Hoffman et al., 2009), respectively in black, and for the five simulations for regions of South America $\left(50-70^{\circ} \mathrm{W}\right.$ and $\left.5-15^{\circ} \mathrm{S}\right)$, North America $\left(60-90^{\circ} \mathrm{W}\right.$ and $\left.25-45^{\circ} \mathrm{N}\right)$, West Africa $\left(20-0^{\circ} \mathrm{W}\right.$ and $\left.5-15^{\circ} \mathrm{N}\right)$, West Pacific $\left(170-190^{\circ} \mathrm{E}\right.$ and $\left.5-15^{\circ} \mathrm{S}\right)$, China $\left(95-125^{\circ} \mathrm{E}\right.$ and $\left.20-45^{\circ} \mathrm{N}\right)$, and India $\left(65-95^{\circ} \mathrm{E}\right.$ and $5-35^{\circ} \mathrm{N}$ ) in color as indicated by the legend. Error bars representing uncertainty in the retrievals are also in black. Simulations are described in Table 1. Legend applies to all panels.

mean seasonal precipitation cycles from the Global Precipitation Climatology Project (GPCP) data set (Adler et al., 2003; Hoffman et al., 2009). Appendix B includes a table, which shows the mean fractional bias between the five simulations and the retrievals, for both AOD and precipitation. Figure 7 shows that the modeled seasonal cycles of both AOD and precipitation agree relatively well with the seasonal cycles from the retrievals. The differences in AOD between the five simulations are generally within the range of the uncertainty in the AOD retrieval, which is indicated by the error bars shown in Fig. 7. The greatest magnitude in the AOD differences between the simulations tends to occur during the seasons of highest precipitation. This greater uncertainty in simulated AOD related to the entrained aerosol scavenging parameterization during seasons with greater rainfall is expected since deeper convective clouds are likely to develop during rainy seasons. Thus, the parameterization for the scavenging of the aerosols entrained above convective cloud bases is increasingly relevant.
Figure 7 shows that the rainy season for South America occurs during the Austral summer in January, February and March. For South America, simulations CF_loimp and CF_base predict as much as a factor of two greater $\mathrm{AOD}$ in the rainy season relative to the other simulations, indicating the uncertainty in regional, seasonal mean AOD that can be attributed to assumptions about the wet removal of entrained aerosols. Peak biomass burning emissions occur around September in this region and the underprediction in our model is greater than the uncertainty in AOD related to the entrained aerosol wet scavenging parameterization. Further, the precipitation is reasonably predicted at that time. This suggests an error in the emissions for this period. Hoelzemann et al. (2009) did not find an interannual longterm trend in AOD, so we would not expect that the slight mismatch between the dates for our AOD data set (2001 to 2006) and the year of our emissions data (2000) should be an issue. We note that the model tends to 
overestimate the precipitation in the rainy seasons and underestimates the precipitation in drier seasons.

Figure 7 shows that the seasonal cycle of AOD is not as pronounced in North America and there is an absence of a pronounced rainy season. We note that the uncertainty in the AOD attributed to the convective wet scavenging parameterization is greatest during the summer months (by a factor of two). This is expected since convective precipitation is greater during these months. Thus, we expect a greater AOD sensitivity to convective wet scavenging parameterizations in the North American summer.

For West Africa, the seasonal cycle of precipitation and AOD are captured reasonably well by the model. However, the model underestimates the AOD for this region. This could reflect too low dust emissions as we noted on examination of Fig. 2. However, the precipitation is also overestimated for this region near the Sahel during the rainy season. This can also contribute to the AOD underestimation. The uncertainty in AOD attributed to the scavenging of entrained aerosols is close to the magnitude of the error bars.

The region near the dateline in the tropical West Pacific, south of the equator is also presented in Fig. 7. This region is characterized by high precipitation through all seasons, but is drier in the austral winter. The retrieved AOD does not show a strong seasonal cycle and the model gives a similar result. There is a factor of two uncertainty in AOD attributed to the wet scavenging parameterization for entrained aerosols. The AOD difference between simulations is greatest during the rainy season when deeper convection is expected, and hence the AOD is expected to be more sensitive to the scavenging parameterization for the entrained aerosols. Precipitation is generally over-estimated for this region during the rainy season, which suggests that a close match with the retrieved AOD might be associated with either an over-estimation of sea salt emissions or an under-vigorous wet scavenging parameterization. We also find the greatest precipitation magnitude differences between the simulations for this cleaner ocean environment relative to the other regions considered.

Figure 7 shows that AOD is underestimated over China region. Henriksson et al. (2011) present a similar result, considering the same region as for our study. We find that the uncertainty associated with the convective wet scavenging parameterization for entrained aerosols is not large enough to account for the AOD underestimation in China. We do note that the precipitation appears to be overestimated over this China region and that can contribute to the AOD underestimation, in addition to the possibility of missing aerosol emissions.

Figure 7 shows that India has a strong seasonal cycle of both AOD and precipitation. The ECHAM5-HAM model has recently been shown to underestimate the regional AOD for the entire seasonal cycle over India (Henriksson et al., 2011). We present the same finding in Fig. 7. The uncertainty in AOD associated with the wet scavenging parameterization for entrained aerosols is less than the magnitude of the under-prediction by the model. Unlike in South America, the maximum AOD and precipitation are coincident in the seasonal cycle for India. This is due to a maximum in natural aerosol emissions due to higher wind speeds in the summer. The model tends to overestimate the precipitation in the rainy season and this contributes to the underestimation of AOD. Relative differences between five simulations are greater between November and January when anthropogenic aerosol emissions peak. These fine mode anthropogenic aerosols appear to be more sensitive to parameterization for the wet scavenging of entrained aerosols. The natural coarse dust mode aerosols emitted during the summer, tend to remain closer to the surface and thus exhibit less relative sensitivity to the parameterization of wet removal of entrained aerosols at higher altitudes in deep convective clouds.

The uncertainty in predicted aerosol wet removal, concentrations, burdens, lifetimes and AOD in the ECHAM5-HAM global model attributed to assumptions about the wet scavenging of aerosols entrained above convective cloud bases motivates the ongoing need to evaluate and improve the representations of the convective wet scavenging processes in global models. Particularly for convective clouds, improvement of the representation of impaction processes, in addition to aerosol activation processes, is found to be relevant.

\section{Conclusions}

In this study, we quantified the uncertainty in aerosol concentrations, burdens, optical depth, and wet deposition associated with convective wet scavenging parameterizations for aerosols entrained above convective cloud bases in a global aerosol-climate model (ECHAM5-HAM). We examined the contribution of aerosols entrained above convective cloud bases to aerosol wet removal in the ECHAM5-HAM model. To facilitate this study, we introduced into the model an explicit representation of the aerosol mass and number contained in convective cloud droplets and ice crystals for the purpose of wet scavenging. This calculated cloud-dropletborne and ice-crystal-borne aerosol scheme considers the processes of activation, collisions, freezing, evaporation, autoconversion, accretion and aggregation as parameterized by the convective microphysics scheme of Lohmann (2008). This development was implemented in replacement of (and compared with) the prescribed cloud-droplet-borne and icecrystal-borne aerosol fraction wet scavenging scheme of the standard model.

Uncertainty remains about how to best represent the processes that aerosols undergo after entrainment into convective updrafts above cloud bases in a global model. In this study we implemented limiting assumptions for the possibility of these aerosols to be either negligibly scavenged or to undergo wet removal subsequent to either activation or impaction scavenging processes. A $20 \%$ to $35 \%$ uncertainty in simulated global, annual mean aerosol burdens and 
optical depth was attributed to different limiting assumptions about the wet scavenging of aerosols entrained above convective cloud bases. A one order of magnitude uncertainty in simulated zonal, annual mean upper tropospheric aerosol mass concentrations was attributed to the assumptions related to the scavenging of entrained aerosols. A major fraction of aerosol mass emission occurs in regions dominated by convective precipitation. This contributes to the sensitivity of aerosol burdens to convective wet scavenging parameterizations. The prescribed fraction scheme of the standard model yielded the lowest global, annual mean aerosol burdens (about $10 \%$ lower than for the assumption of entrained aerosol activation or size-dependent impaction scavenging).

Aerosols entrained above convective cloud bases contributed as much as $20 \%$ to $50 \%$ of the simulated global, annual mean convective wet deposition in the ECHAM5HAM model, depending on the aerosol species. Assuming that aerosol activation occurs only at convective cloud base, then this fraction is attributed to impaction scavenging in convective clouds, which suggests that impaction scavenging could control wet deposition relatively more for convective clouds for stratiform clouds.

The extent that entrained aerosols should be scavenged by activation processes in a global aerosol-climate model remains unclear, although the possibility to maintain sufficient supersaturation for the entrained aerosols to activate is perhaps less likely than the possibility for scavenging by impaction. Sulfate, and carbonaceous aerosols have a major fraction of their mass in the accumulation mode, which is not as efficiently scavenged by impaction processes, but is efficiently scavenged by activation. As a result for our simulations, the global, annual mean mass burdens for these species were lower by about $10 \%$ under the assumption that soluble/internally mixed entrained aerosols could activate as opposed to being scavenged by impaction.

Relative to the standard model with prescribed clouddroplet-borne and ice crystal-borne aerosol fractions, all explicit treatments of cloud-droplet-borne and ice-crystalborne aerosol mass and number reduced global, annual mean aerosol wet removal in mixed-phase clouds between a factor of two and five. This reflected the simulated release of aerosols as cloud droplets evaporated during the BergeronFindeisen process. A single prescribed fraction as a function of aerosol mode, applied for the entire temperature range (as for the standard model) is not consistent with these convective cloud microphysical processes.

Wet scavenging parameterizations were shown to have feedbacks on cloud properties and precipitation in the ECHAM5-HAM model. Vigorous wet scavenging of accumulation and coarse mode aerosols entrained above convective cloud bases contributed to a $20 \%$ reduction in annual and global mean accumulation and coarse mode number burdens in the ECHAM5-HAM model. This scavenginginduced aerosol number burden reduction promoted a $20 \%$ increase in the global, annual mean number of nucleation and
Aitken mode particles (particularly when coupled with less vigorous scavenging parameterization for uptake of Aitken mode aerosols into cloud droplets). This number burden change was associated with a concurrent increase in both the stratiform and convective cloud droplet number concentration in the model. Global and annual mean stratiform and convective precipitation increased and decreased, respectively by $15 \%$, while total precipitation was changed by less than $1 \%$. The precipitation response is tightly coupled with the moisture availability to the stratiform and convective schemes, which is predicted with uncertainty in global models. Future work should include simulations with a chemicalaerosol transport model to exclude the feedbacks on precipitation and isolate the pure impact of alternative convective parameterizations on the simulated aerosol burdens.

The geographic distribution of the wet deposition changes under the different wet scavenging assumptions for entrained aerosols was driven by the scavenging assumption changes as opposed to the precipitation changes in the ECHAM5-HAM. Sea salt deposition changes in the tropics were the one exception, which were more strongly driven by precipitation changes in the model. Regional and seasonal cycles of AOD and precipitation were also examined for six regions. The uncertainty in the simulated monthly, regional mean AOD attributed to the scavenging parameterization was shown to be greatest during rainy seasons (factor of two), but was close to the estimated error for the AOD retrievals.

This study has quantified the uncertainty in simulated aerosol concentrations and lifetimes in a global model attributed to assumptions about the wet scavenging of aerosols entrained above convective cloud bases. These findings motivate the ongoing need to develop knowledge about convective wet scavenging processes, and to evaluate and improve their representation in global models. This is particularly relevant since there are major aerosol sources in regions dominated by convective precipitation. For the global modeling of aerosol convective wet removal, improvement to the representation of impaction processes, in addition to activation processes, is relevant.

\section{Appendix A}

\section{Convective in-cloud aerosol wet scavenging parameterizations}

\section{A1 Standard ECHAM5-HAM convective in-cloud aerosol wet scavenging: prescribed fractions}

In the convective updrafts, the fraction of aerosol mass and number that is cloud-droplet borne and ice-crystal borne is prescribed as a function of the aerosol mode for the purposes of the wet removal parameterization. The prescribed fractions, $R_{i}$, are given in Table 2 . Note that the prescribed fractions are applied to the in-updraft aerosol concentrations. 
Table A1. Mean fractional bias between the regional, monthly mean aerosol optical depth (AOD) retrieval of van Donkelaar et al. (2010) and the five simulations (top half of table). Mean fractional bias between the regional, monthly mean precipitation of the Global Precipitation Climatology Project retrieval (Adler et al., 2003; Hoffman et al., 2009) and the five simulations (bottom half of table). Seasonal cycles are shown in Fig. 7.

\begin{tabular}{lrrrrrr}
\hline & India & East Asia & West Pacific & South America & North America & West Africa \\
\hline AOD & & & & & & \\
PF_std & -0.57 & -0.34 & -0.13 & -0.39 & -0.09 & -0.35 \\
CF_loimp & -0.20 & -0.11 & 0.59 & 0.23 & 0.32 & -0.003 \\
CF_base & -0.20 & -0.08 & 0.58 & 0.15 & 0.32 & -0.05 \\
CF_act & -0.41 & -0.19 & 0.12 & -0.18 & 0.16 & -0.17 \\
CF_hiimp & -0.42 & -0.20 & -0.12 & -0.21 & 0.09 & -0.29 \\
\hline Precipitation & & & & & & \\
PF_std & -0.07 & 0.43 & 0.31 & -0.23 & -0.01 & -0.25 \\
CF_loimp & 0.02 & 0.47 & 0.12 & -0.21 & -0.08 & -0.28 \\
CF_base & -0.10 & 0.50 & 0.21 & -0.22 & -0.04 & -0.36 \\
CF_act & -0.22 & 0.47 & 0.30 & -0.37 & -0.07 & -0.24 \\
CF_hiimp & -0.03 & 0.47 & 0.25 & -0.18 & -0.03 & -0.13 \\
\hline
\end{tabular}

In one timestep the updraft column is considered from the base and moving upwards. Thus, the in-updraft aerosol concentrations are parameterized to equal the underlying layer aerosol concentration at that same time step, modified by entrainment and detrainment. Within the $i$-th aerosol mode, $R_{i}$ is the same for ice crystals and for cloud droplets, and independent of cloud temperature. The change in the $j$-th inupdraft tracer concentration due to convective wet deposition at each model layer $(k)$ is

$\Delta C_{j, k}=C_{j, k}^{\text {liq }} R_{i} E^{\text {liq }}+C_{j, k}^{\text {ice }} R_{i} E^{\text {ice }}$

where $C_{j, k}^{\text {liq }}$ and $C_{j, k}^{\text {ice }}$ are the $j$-th in-updraft tracer concentrations associated with the liquid and ice phase respectively, at model level $k, E^{\text {liq }}$ and $E^{\text {ice }}$ are the fractions of liquid and ice water, respectively, that are converted to precipitation. This standard model scheme allows for scavenging in liquid, mixed-phase and ice clouds since tracer concentrations associated with the liquid and ice phase can co-exist.

For each model layer, a grid box mean tracer deposition flux $\overline{F_{j, k}^{\text {dep }}}$ is found

$\overline{F_{j, k}^{\text {dep }}}=\Delta C_{j, k} \overline{F_{k}^{\text {up }}}$

where $\overline{F_{k}^{\text {up }}}$ is the grid box mean updraft mass flux at model layer $k$. The grid box mean tracer tendency is

$\frac{\overline{\Delta C_{j, k}}}{\Delta t}=\overline{F_{j, k}^{\mathrm{dep}}} \frac{g}{\Delta p}$

where $g$ is the acceleration due to gravity and $\Delta p$ is the model layer thickness in pressure units. The tracer deposition fluxes are integrated from the model top downward. The mean updraft tracer flux for the $j$-th tracer is recalculated as

$\overline{F_{j, k}^{\mathrm{up}}}=\left(C_{j, k}-\Delta C_{j, k}\right) \overline{F_{k}^{\mathrm{up}}}$.
Finally, the fraction of evaporating precipitation is used to reduce the integrated tracer deposition flux as described in detail in Stier et al. (2005). This parameterization is implemented in simulation PF_std.

\section{A2 Revised convective in-cloud aerosol wet scavenging: calculated fractions}

The mass and number of cloud-droplet-borne aerosols for each aerosol mode is first diagnosed at the cloud base using the aerosol activation parameterization. For all simulations of this study, the Ghan et al. (1993) activation scheme is implemented at convective cloud base. This activation scheme does not implicitly account for the reduction in the number of activated droplets that can occur above cloud base due to entrainment of subsaturated air and cloud droplet detrainment. However, evaporation of cloud liquid water content due to entrainment is included in our model. Additionally, the number of activated droplets passed up to an overlying model layer does decay due to autoconversion and accretion processes and as the ratio of the mass fluxes of adjacent layers decays. Aerosol activation parameterizations suitable for the various types of convection in global models (shallow, mid-level, and deep) are still under development, and remain an uncertainty for the simulation of convective cloud droplet number concentrations in global models. However, adiabatic activation parameterizations can correctly simulate the number of activated aerosols at convective cloud bases in as much as the parameterization for cloud updraft velocity is correct (Meskhidze et al., 2005). For our simulations, the number of activated droplets is

$N_{\text {l,ghan }}=\frac{\omega N_{\mathrm{aer}>25 \mathrm{mn}}}{\omega+\beta N_{\mathrm{aer}>25 \mathrm{~nm}}}$ 
where $N_{\text {aer }}>25 \mathrm{mn}$ is the number of soluble/internally mixed aerosols larger than $25 \mathrm{~nm}$ in radii, $\beta$ is $0.0034 \mathrm{~cm}^{4} \mathrm{~s}^{-1}$, and $w$ is the vertical velocity used by the activation scheme. Lohmann (2008) and Lohmann (2002) further describe the parameterization of vertical velocity for the purposes of the activation scheme.

For the purposes of wet scavenging, the number of activated aerosols at cloud base is apportioned between the aerosol modes, and separate cloud-droplet-borne mass fractions are calculated as described in detail in Croft et al. (2010). For simulation CF_loimp, the remaining interstitial aerosols and those aerosols entrained above cloud base can become cloud-droplet borne or ice-crystal borne by collision processes via the Hoose et al. (2008) collision kernels, which are based on a Brownian diffusion model that uses a zero collision efficiency for the coarse mode. The aerosol mass and number that are cloud-droplet borne, ice-crystal borne and in the interstitial phase for each mode are treated as separate variables in our model in order to calculate the wet removal of the aerosol mass and number for each mode within the context of the convective tracer transport scheme. These auxiliary variables are not passed between time-steps in our model since the convective clouds collapse after each timestep.

Within each model time-step, considering the model vertical column from the cloud base and moving upwards, the predicted cloud droplet number concentration (CDNC) at a given vertical level is set equal to the CDNC of underlying model layer modified by the ratio of the mass fluxes of adjacent layers and modified at each vertical level based on the microphysical conversion rates for freezing, autoconversion and accretion. Likewise, the ice crystal number concentration (ICNC) is set equal to that of the underlying layer modified by the ratio of the mass fluxes of adjacent layers, and modified at each vertical level based on the microphysical conversion rates for freezing, aggregation and accretion. The cloud-droplet-borne and ice-crystal-borne aerosol mass and number are treated in a likewise fashion. Aerosols are released to the interstitial phase by cloud droplet evaporation due to the Bergeron-Findeisen process.

The equation that governs the cloud-droplet-borne aerosol mass for the $j$-th aerosol mode and for the model level $k$ is

$$
\begin{aligned}
& m_{j, k, \mathrm{CDCV}}=m_{j, k-1, \mathrm{CDCV}}+\Delta m_{j, k, \mathrm{coll}}-\Delta m_{j, k, \mathrm{frz}} \\
& \quad-\Delta m_{j, k, \mathrm{BFP}}-\Delta m_{j, k, \text { auto }}-\Delta m_{j, k, \text { acc }}
\end{aligned}
$$

where $m_{j, k-1, \mathrm{CDCV}}$ is the cloud-droplet-borne aerosol mass from the underlying model layer (scaled by the ratio of the mass fluxes of adjacent layers), and the mass change is $\Delta m_{j, k, \text { coll }}$ due to collisions between cloud droplets and interstitial aerosols, $\Delta m_{j, k \text {,frz }}$ due to freezing, $\Delta m_{j, k, \mathrm{BFP}}$ due to evaporation during the Bergeron-Findeisen process, and $\Delta m_{j, k \text {,auto }}$ and $\Delta m_{j, k, \text { acc }}$ due to autoconversion and accretion, respectively. Similar processes are considered for the cloud-droplet-borne aerosol number.
The equation that governs the ice-crystal-borne aerosol mass for the $j$-th mode and for the model level $k$ is

$$
\begin{aligned}
& m_{j, k, \mathrm{ICCV}}=m_{j, k-1, \mathrm{ICCV}}+\Delta m_{j, k, \mathrm{colli}}+\Delta m_{j, k, \mathrm{frz}} \\
& \quad-\Delta m_{j, k, \text { agg }}-\Delta m_{j, k, \text { acci }}
\end{aligned}
$$

where $m_{j, k-1, \text { ICCV }}$ is the ice-crystal-borne aerosol mass from the underlying model layer (scaled by the ratio of the mass fluxes of adjacent layers), and the mass change is $\Delta m_{j, k, \text { colli }}$ due to collisions between ice crystals and interstitial aerosols, $\Delta m_{j, k, \text { frz }}$ due to freezing, and $\Delta m_{j, k, \text { agg }}$ and $\Delta m_{j, k \text {,acci }}$ due to aggregation and accretion, respectively. There is a similar treatment for the aerosol number that is ice-crystal borne.

The interstitial aerosol mass is

$$
\begin{aligned}
& m_{j, k, \text { inter }}=m_{j, k-1, \text { inter }}+\Delta m_{j, k, \mathrm{BFP}}-\Delta m_{j, k, \mathrm{coll}} \\
& \quad-\Delta m_{j, k, \mathrm{colli}}
\end{aligned}
$$

where $m_{j, k-1 \text {,inter }}$ is the interstitial aerosol mass from the underlying model layer (scaled by the ratio of the mass fluxes of adjacent layers) modified by aerosol entrainment and detrainment. The interstitial aerosol number is treated similarly.

Following this diagnosis of the cloud-droplet-borne and ice-crystal-borne aerosol, the convective wet scavenging parameterization can proceed similarly to that for the standard model, within the context of the convective tracer transport scheme. However, the cloud-droplet-borne and ice-crystalborne fractions are explicitly diagnosed for each $j$-th inupdraft tracer and each model level $(k)$, and also separately for the liquid and ice phase. The cloud-droplet-borne aerosol mass fraction is

$$
R_{j, k, \text { liq }}=\frac{m_{j, k, \mathrm{CDCV}}}{m_{j, k, \mathrm{CDCV}}+m_{j, k, \mathrm{ICCV}}+m_{j, k, \text { inter }}}
$$

and the ice-crystal-borne aerosol mass fraction is

$$
R_{j, k, \text { ice }}=\frac{m_{j, k, \mathrm{ICCV}}}{m_{j, k, \mathrm{CDCV}}+m_{j, k, \mathrm{ICCV}}+m_{j, k, \text { inter }}}
$$

There is a similar treatment for the aerosol number tracers. The change of the $j$-th tracer due to convective wet deposition at model level $k$ is

$$
\Delta C_{j, k}=C_{j, k}^{\mathrm{liq}} R_{j, k, \text { liq }} E^{\mathrm{liq}}+C_{j, k}^{\mathrm{ice}} R_{j, k, \text { ice }} E^{\mathrm{ice}} .
$$

This is the wet scavenging implemented for the simulation CF_loimp. A similar scheme is employed for simulation CF hiimp except that impaction scavenging is treated with the size-dependent impaction parameterization of Croft et al. (2010) as opposed to the Hoose et al. (2008) prescribed kernels. The CF_loimp scheme is also employed for simulation CF_base except that wet removal is limited to those aerosols entering at cloud base.

For the sensitivity simulation $\mathrm{CF}_{-}$act we assume that $100 \%$ of the soluble/internally mixed aerosols entrained above cloud base and having radii greater than $25 \mathrm{~nm}$ can participate in the Ghan et al. (1993) activation scheme. This 
activation scheme is thus applied at each model level from the cloud base layer upwards. At each time step considering the model vertical column from the cloud base upwards, the cloud droplet number concentration is equal to that of the underlying layer modified by the microphysical processes that we described earlier in this section and additionally by the number of newly formed cloud droplets at that level. The supersaturation required to activate entrained aerosols could develop if the entrained air parcel accelerates and is exposed to low cloud droplet surface area either because there is negligible mixing with the existing updraft air, or rainout or dilution has reduced the CDNC. It is not clear how often these conditions occur in convective clouds. Although there is some evidence that entrained aerosols may activate to form new and small cloud droplets (Pinsky and Khain, 2002; Fridlind et al., 2004; Freud et al., 2011). We will use this assumption of activation of entrained aerosols as a limiting case. We note that neither supersaturation, nor updraft velocity can be explicitly resolved with the coarse resolution of a global model. Rather, these are parameterized quantities in global models. Detrainment of cloud droplets is also allowed at each vertical level following the same treatment as for the aerosol detrainment.

These additional terms due to activation of aerosols entrained above cloud base, and detrainment are used to adjust the convective CDNC and resultant cloud-droplet-borne aerosol mass and number variables,

$$
\begin{aligned}
& m_{j, k, \mathrm{CDCV}}=m_{j, k-1, \mathrm{CDCV}}+\Delta m_{j, k, \text { act }, \text { ent }}+\Delta m_{j, k, \text { coll }} \\
& \quad-\Delta m_{j, k, \mathrm{frz}}-\Delta m_{j, k, \mathrm{BFP}}-\Delta m_{j, k, \text { auto }}-\Delta m_{j, k, \text { acc }} \\
& \quad-\Delta m_{j, k, \mathrm{det}}
\end{aligned}
$$

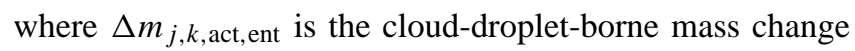
due to entrained aerosols becoming activated and $\Delta m_{j, k \text {, det }}$ is the change due to detrainment of the cloud droplets. There is a similar treatment for aerosol number in the cloud droplets. This is the wet scavenging implemented for the simulation CF_act.

For all simulations of this study, the prescribed entrainment rates in our model for shallow, mid-level and penetrative convection are $1 \times 10^{-3}, 1 \times 10^{-4}$, and $2 \times 10^{-4} \mathrm{~m}^{-1}$, respectively. Further details about the calculation of entrainment and detrainment rates are given in Tiedtke (1989) and Nordeng (1994). Detrainment occurs primarily at the two uppermost cloud levels, and is parameterized based on the predicted cloud top altitude.

\section{Appendix B}

\section{Aerosol optical depth and precipitation: additional model and retrieval comparisons}

This appendix includes a statistical analysis related to Fig. 7 . Table A1 summarizes the mean fractional bias (Boylan and Russell, 2006) between the modeled and retrieved aerosol optical depth (AOD) and also between the modeled and retrieved precipitation for the six regions under consideration in Sect. 3.6. For the mean fractional bias statistic, relatively large fractional differences for low either AOD or precipitation can dominate the result relative to relatively smaller fractional differences at larger AOD or precipitation, despite a larger magnitude in the absolute difference.

Acknowledgements. The authors thank Annika Ekman, Johann Feichter, Till Wagner, and Daniel Cziczo for helpful discussions. We thank Sylvaine Ferrachat for her technical assistance and Aaron van Donkelaar for providing the MODIS/MISR/AERONET AOD compilation data set. We thank the National Science and Engineering Research Council of Canada (NSERC), the Killam Trusts Foundation of Canada, and the Atlantic Computational Excellence Network (ACE-Net) for financial support. Thanks to CSCS for computing time. The authors also thank the two reviewers for their constructive comments, which have contributed to the development of this manuscript.

Edited by: H. Tost

\section{References}

Ackerman, A. S., Toon, O. B., Stevens, D. E., Heymsfield, A. J., Ramanathan, V., and Welton, E. J.: Reduction in tropical cloudiness by soot, Science, 288, 1042-1047, doi:10.1126/science.288.5468.1042, 2000.

Adler, R. F., Huffman, G. J., Chang, A., Ferraro, R., Xie, P. P., Janowiak, J., Rudolf, B., Schneider, U., Curtis, S., Bolvin, D., Gruber, A., Susskind, J., Arkin, P., and Nelkin, E.: The version-2 global precipitation climatology project (GPCP) monthly precipitation analysis (1979-present), J. Hydrometeor., 4, 1149-1167, 2003.

Andreae, M. O., Rosenfeld, D., Artaxo, P., Costa, A. A., Frank, G. P., Longo, K. M., and Silva-Dias, M. A. F.: Smoking rain clouds over the Amazon, Science, 303, 1337-1342, 2004.

Arakawa, A.: The cumulus parameterization problem: past, present and future, J. Climate, 17, 2493-2525, 2004.

Boylan, J. W. and Russell, A. G.: PM and light exntinction model performance metrics, goals, and criteria for three-dimensional air quality models, Atmos. Environ., 40, 4926-4959, 2006.

Cagnazzo, C., Manzini, E., Giorgetta, M. A., Forster, P. M. De F., and Morcrette, J. J.: Impact of an improved shortwave radiation scheme in the MAECHAM5 General Circulation Model, Atmos. Chem. Phys., 7, 2503-2515, doi:10.5194/acp-7-2503-2007, 2007.

Charlson, R. J., Schwartz, S. E., Hales, J. M., Cess, R. D., Coakley, J. A., Hansen, J. E., and Hofmann, D. J.: Climate forcing by anthropogenic aerosols, J. Geophys. Res., 255, 423-430, 1992.

Croft, B., Lohmann, U., Martin, R. V., Stier, P., Wurzler, S., Feichter, J., Posselt, R., and Ferrachat, S.: Aerosol size-dependent below-cloud scavenging by rain and snow in the ECHAM5HAM, Atmos. Chem. Phys., 9, 4653-4675, doi:10.5194/acp-94653-2009, 2009.

Croft, B., Lohmann, U., Martin, R. V., Stier, P., Wurzler, S., Feichter, J., Hoose, C., Heikkilä, U., van Donkelaar, A., and 
Ferrachat, S.: Influences of in-cloud aerosol scavenging parameterizations on aerosol concentrations and wet deposition in ECHAM5-HAM, Atmos. Chem. Phys., 10, 1511-1543, doi:10.5194/acp-10-1511-2010, 2010.

Dentener, F., Kinne, S., Bond, T., Boucher, O., Cofala, J., Generoso, S., Ginoux, P., Gong, S., Hoelzemann, J. J., Ito, A., Marelli, L., Penner, J. E., Putaud, J.-P., Textor, C., Schulz, M., van der Werf, G. R., and Wilson, J.: Emissions of primary aerosol and precursor gases in the years 2000 and 1750 prescribed data-sets for AeroCom, Atmos. Chem. Phys., 6, 4321-4344, doi:10.5194/acp-64321-2006, 2006.

Dockery, D. W., Pope III, C. A., Xu, X., Spengler, J. D., Ware, J. H., Fay, M. E., Ferris, B. G., and Speizer, F. E.: An association between air pollution and mortality in six U.S. Cities, N. Engl. J. Med., 329, 1753-1759, 1993.

Donner, L. J., Wyman, B. L., Hemler, R. S., Horowitz, L. W., Ming, Y., Zhoa, M., Golaz, J.-C., Ginoux, P., Lin, S.-J., Schwarkopf, M. D., Austin, J., Alaka, G., Cooke, W. F., Delworth, T. L., Freidenreich, S. M., Gordon, C. T., Griffies, S. M., Held, I. M., Hurlin, W. J., Klein, S. A., Knutson, T. R., Langenhorst, A. R., Lee, H.-C., Lin, Y., Magi, B. I., Malyshev, S. L., Milly, P. C. D., Naik, V., Nath, M. J., Pincus, R., Ploshay, J. J., Ramaswamy, V., Seman, C. J., Shevliakova, E., Sirutis, J. J., Stern, W. F., Stouffer, R. J., Stouffer, R. J., Wilson, R. J., Winton, M., Wittenberg, A. T., and Zeng, F.: The dynamical core, physical parameterizations, and basic simulation characteristics of the atmospheric component AM3 of the GFDL Global Coupled Model CM3, J. Climate, 24, 3484-3519, 2011.

Engström, A., Ekman, A. M. L., Krejci, R., Ström, J., de Reus, M., and Wang, C.: Observational and modelling evidence of tropical deep convective clouds as a source of mid-tropospheric accumulation mode aerosols, Geophys. Res. Lett., 35, L23813, doi:10.1029/2008GL035817, 2008.

Fang, Y., Fiore, A. M., Horowitz, L. W., Gnanadesikan, A., Held, I., Chen, G., Vecchi, G., and Levy, H.: The impacts of changing transport and precipitation on pollutant distributions in a future climate, J. Geophys. Res., 116, D18303, doi:10.1029/2011JD015642, 2011.

Ferraro, R., Weng, F., Grody, N., and Basist, A.: An Eight Year (1987-1994) Time Series of Rainfall, Clouds, Water Vapor, Snow-cover, and Sea-ice Derived from SSM/I Measurements, B. Am. Meteorol. Soc., 77, 891-905, 1996.

Freud, E. and Rosenfeld, D.: Linear relation between convective cloud drop number concentration and depth for rain initiation, J. Geophys. Res., 117, D02207, doi:1029/2011JD016457, 2012.

Freud, E., Rosenfeld, D., and Kulkarni, J. R.: Resolving both entrainment-mixing and number of activated $\mathrm{CCN}$ in deep convective clouds, Atmos. Chem. Phys., 11, 12887-12900, doi:10.5194/acp-11-12887-2011, 2011.

Fridlind, A., Ackermann, A., Jensen, E., and Stevens, D.: Evidence for the predominance of mid-tropospheric aerosols as subtropical anvil nuclei, Science, 304, 718-722, 2004.

Ghan, S. J., Chuang, C. C., and Penner, J. E.: A parameterization of cloud droplet nucleation. Part I: Single aerosol type, Atmos. Res., 30, 198-221, 1993.

Greenfield, S.: Rain scavenging of radioactive particulate matter from the atmosphere., J. Meteorol., 14, 115-125, 1957.

Greenwald, T. J., Stephens, G. L., Vonder Haar, T. H., and Jackson, D. L.: A Physical Retrieval of Cloud Liquid Water Over the
Global Oceans Using Special Sensor Microwave/Imager (SSM/I) Observations, J. Geophys. Res., 98, 18471-18488, 1993.

Han, Q., Rossow, W. B., Chou, J., and Welch, R.: Global variation of column droplet concentration in low-level clouds, Geophys. Res Lett., 25, 1419-1422, 1998.

Hansen, J., Sato, M., and Ruedy, R.: Radiative forcing and climate response, J. Geophys. Res., 102, 6831-6864, doi:10.1029/96JD03436, 1997.

Henriksson, S. V., Laaksonen, A., Kerminen, V.-M., Räisänen, P., Järvinen, H., Sundström, A.-M., and de Leeuw, G.: Spatial distributions and seasonal cycles of aerosols in India and China seen in global climate-aerosol model, Atmos. Chem. Phys., 11, 79757990, doi:10.5194/acp-11-7975-2011, 2011.

Hoelzemann, J., Longo, K. M., Fonseca, R. M., do Rosario, N. M. E., Elbern, H., Freitas, S. R., and Pires, C.: Regional representativity of AERONET observation sites during the biomass burning season in South America determined by correlation studies with MODIS Aerosol Optical Depth, J. Geophys. Res., 114, D13301, doi:10.1029/2008JD010369, 2009.

Hoffman, G. J., Adler, R. F., Bolvin, D. T., and Gu, G.: Improving the global precipitation record: GPCP Version 2.1, Geophys. Res. Lett., 36, L17808, doi:10.1029/2009GL040000, 2009.

Hoose, C., Lohmann, U., Bennartz, R., Croft, B., and Lesins, G.: Global simulations of aerosol processing in clouds, Atmos. Chem. Phys., 8, 6939-6963, doi:10.5194/acp-8-6939-2008, 2008.

Khairoutdinov, M. and Kogan, Y.: A new cloud physics parameterization in a large-eddy simulation model of marine stratocumulus, Mon. Weather Rev., 128, 229-243, 2000.

Korolev, A.: Limitations of the Wegener-Bergeron-Findeisen mechanism in the evolution of mixed-phase clouds, J. Atmos. Sci., 64, 3372-3375, doi:10.1175/JAS4035.1, 2007.

Korolev, A. V., Emery, E. F., Strapp, J. W., Cober, S. G., Isaac, G. A., Wasey, M., and Marcotte, D.: Small ice particles in tropospheric clouds: Fact or artifact, B. Am. Meteorol. Soc., 92, 967-973, 2011.

Levkov, L., Eppel, D. P., and Grassl, H.: Modeling the atmospheric transport of trace-metals including the role of precipitating clouds, Atmos. Environ., 25, 779-789, 1991.

Lin, H. and Leaitch, W. R.: Development of an in-cloud aerosol activation parameterization for climate modelling, in: Proceedings of the WMO Workshop on Measurement of Cloud Properties for Forecasts of Weather, Air Quality and Climate, World Meteorol. Organ., Geneva, 328-335, 1997.

Lin, S. J. and Rood, R. B.: Multidimensional flux form semiLagrangian transport, Mon. Weather Rev., 124, 2046-2068, 1996.

Liu, H., Jacob, D. J., Bey, I., and Yantosca, R. M.: Constraints from ${ }^{210} \mathrm{~Pb}$ and ${ }^{7} \mathrm{Be}$ on wet deposition and transport in a global threedimensional chemical tracer model driven by assimilated meteorolgical fields, J. Geophys. Res., 106, 12109-12128, 2001.

Lohmann, U.: A glaciation indirect aerosol effect caused by soot aerosols, Geophys. Res. Lett., 29, 1052, doi:10.1029/2001GL014357, 2002.

Lohmann, U.: Global anthropogenic aerosol effects on convective clouds in ECHAM5-HAM, Atmos. Chem. Phys., 8, 2115-2131, doi:10.5194/acp-8-2115-2008, 2008.

Lohmann, U. and Kärcher, B.: First interactive simulations of cirrus clouds formed by homogeneous freezing in the 
ECHAM general circulation model, J. Geophys. Res., 107, 4105, doi:10.1029/2001JD000767, 2002.

Lohmann, U., Stier, P., Hoose, C., Ferrachat, S., Kloster, S., Roeckner, E., and Zhang, J.: Cloud microphysics and aerosol indirect effects in the global climate model ECHAM5-HAM, Atmos. Chem. Phys., 7, 3425-3446, doi:10.5194/acp-7-3425-2007, 2007.

Menon, S. and Rotstayn, L.: The radiative influence of aerosol effects on liquid-phase cumulus and stratiform clouds based on sensitivity studies with two climate models, Climate Dyn., 27, 345-356, 2006.

Meskhidze, N., Nenes, A., Conant, W. C., and Seinfeld, J. H.: Evaluation of a new cloud droplet activation parameterization with in situ data from CRYSTAL-FACE and CSTRIPE, J. Geophys. Res., 110, D16202, doi:10.1029/2004JD005703, 2005.

Mlawer, E. J., Taubman, S. J., Brown, P. D., Iacono, M. J., and Clough, S. A.: Radiative transfer for inhomogeneous atmosphere: RRTM, a validated correlated-k model for the longwave, J. Geophys. Res., 102, 16663-16682, 1997.

Morales, R., Nenes, A., Jonsson, J., Flagan, R. C., and Seinfeld, J. H.: Evaluation of an entraining droplet activation parameterization using in situ cloud data, J. Geophys. Res., 116, D15205, doi:10.1029/2010JD015324, 2011.

Morcrette, J.-J., Clough, S. A., Mlawer, E. J., and Iacono, M. J.: Impact of a validated radiative transfer scheme, RRTM, on the ECMWF model climate and 10-day forecasts, ECMWF, Reading, UK, technical memorandum 252 edn, 1998.

Nober, F. J., Graf, H.-F., and Rosenfeld, D.: Sensitivity of the global circulation to the suppression of precipitation by anthropogenic aerosols, Global Planet. Change, 37, 57-80, 2003.

Nordeng, T. E.: Extended versions of the convective parameterization scheme at ECWMF and their impact on the mean and transient activity of the model in the tropics, ECMWF, Reading, UK, technical memorandum 206 edn., 1994.

Pinsky, M. and Khain, A.: Effects of in-cloud nucleation and turbulence on droplet spectrum formation in cumulus clouds, Q. J. Roy. Meteorol. Soc., 128, 501-533, 2002.

Piriou, J. M., Redelsperger, J.-L., Geleyn, J.-F., Lafore, J.-P., and Guichard, F.: An approach for convective parameterization with memory: Separating microphysics and transport in grid-scale equations, J. Atmos. Sci., 64, 4127-4139, 2007.

Plant, R. S.: A review of the theoretical basis for bulk mass flux convective parameterization, Atmos. Chem. Phys., 10, 3529-3544, doi:10.5194/acp-10-3529-2010, 2010.

Randall, D., Khairoutdinov, M., Arakawa, A., and Grabowski, W.: Breaking the cloud parameterization deadlock, B. Am. Meteorol. Soc., 84, 1547-1564, 2003.

Randall, D., Wood, R., Bony, S., Colman, R., Fichefet, T., Fyfe, J., Kattsov, V., Pitman, A., Shukla, J., Srinivasan, J., Stouffer, R., Sumi, A., and Taylor, K.: Climate Models and Their Evaluation, in: Climate Change 2007: The Scientific Basis. Contribution of working group I to the Fourth Assessment Report of the Intergovernmental Panel on Climate Change, edited by: Solomon, S., Qin, D., Manning, M., Chen, Z., Marquis, M., Averyt, K. B., Tignor, M., and Miller, H. L., 589-662, Cambridge Univ. Press, Cambridge, United Kingdom and New York, NY, USA, 2007.
Ridley, D. A., Heald, C. L., and Ford, B.: North African dust export and deposition: A satellite and model perspective, J. Geophys. Res., 117, D02202, doi:10.1029/2011JD016794, 2012.

Roeckner, E., Baeuml, G., Bonventura, L., Brokopf, R., Esch, M., Giorgetta, M., Hagemann, S., Kirchner, I., Kornblueh, L., Manzini, E., Rhodin, A., Schlese, U., Schulzweida, U., and Tompkins, A.: The atmospheric general circulation model ECHAM5. Part I: Model description, Report 349, Max Planck Institute for Meteorology, Hamburg, Germany, available at: http: //www.mpimet.mpg.de, 2003.

Rossow, W. B. and Schiffer, R. A.: Advances in understanding clouds from ISCCP, B. Am. Meteorol. Soc., 80, 2261-2287, 1999.

Stevens, B. and Feingold, G.: Untangling aerosol effects on clouds and precipitation in a buffered system, Nature, 461, 607-613, 2009.

Stier, P., Feichter, J., Kinne, S., Kloster, S., Vignati, E., Wilson, J., Ganzeveld, L., Tegen, I., Werner, M., Balkanski, Y., Schulz, M., Boucher, O., Minikin, A., and Petzold, A.: The aerosol-climate model ECHAM5-HAM, Atmos. Chem. Phys., 5, 1125-1156, doi:10.5194/acp-5-1125-2005, 2005.

Textor, C., Schulz, M., Guibert, S., Kinne, S., Balkanski, Y., Bauer, S., Berntsen, T., Berglen, T., Boucher, O., Chin, M., Dentener, F., Diehl, T., Easter, R., Feichter, H., Fillmore, D., Ghan, S., Ginoux, P., Gong, S., Grini, A., Hendricks, J., Horowitz, L., Huang, P., Isaksen, I., Iversen, I., Kloster, S., Koch, D., Kirkevåg, A., Kristjansson, J. E., Krol, M., Lauer, A., Lamarque, J. F., Liu, X., Montanaro, V., Myhre, G., Penner, J., Pitari, G., Reddy, S., Seland, $\varnothing$., Stier, P., Takemura, T., and Tie, X.: Analysis and quantification of the diversities of aerosol life cycles within AeroCom, Atmos. Chem. Phys., 6, 1777-1813, doi:10.5194/acp-6-1777-2006, 2006.

Tiedtke, M.: A comprehensive mass flux scheme for cumulus parameterization in large scale model, Mon. Weather Rev., 117, 1779-1800, 1989.

Tost, H., Lawrence, M. G., Brühl, C., Jöckel, P., The GABRIEL Team, and The SCOUT-O3-DARWIN/ACTIVE Team: Uncertainties in atmospheric chemistry modelling due to convection parameterisations and subsequent scavenging, Atmos. Chem. Phys., 10, 1931-1951, doi:10.5194/acp-10-1931-2010, 2010.

Twomey, S.: Aerosol, clouds, and radiation, Atmos. Environ., 25A, 2435-2442, 1991.

van Donkelaar, A., Martin, R. V., Brauer, M., Kahn, R., Levy, R., Verduzco, C., and Villeneuve, P.: Global estimates of exposure to fine particulate matter concentrations from satellite-based aerosol optical depth, Environ. Health Perspec., 118, 847-855, doi:10.1289/ehp.0901623, 2010.

Wang, P. K., Grover, S. N., and Pruppacher, H. R.: On the effect of electric charges on the scavenging of aerosol particles by clouds and small raindrops, J. Atmos. Sci., 35, 1735-1743, 1978.

Weng, F. and Grody, N. C.: Retrieval of cloud liquid water using the Special Sensor Microwave Imager (SSM/I), J. Geophys. Res., 99, 25535-25551, 1994. 